\title{
EHRA/EAPCI expert consensus statement on catheter-based left atrial appendage occlusion
}

\author{
Bernhard Meier (EAPCI Chairperson) (Switzerland) ${ }^{1}$, Yuri Blaauw \\ (The Netherlands) ${ }^{2}$, Ahmed A. Khattab (Switzerland) ${ }^{1}$, Torsten Lewalter (Germany) ${ }^{3}$, \\ Horst Sievert (Germany) ${ }^{4}$, Claudio Tondo (Italy) ${ }^{5}$, Michael Glikson \\ (EHRA Chairperson) (Israel) ${ }^{6 *}$
}

\section{Document Reviewers: Gregory Y. H. Lip (UK), Jose Lopez-Minguez (Spain), Marco Roffi (Switzerland), Carsten Israel (Germany), Dariusz Dudek (Poland), Irene Savelieva (on behalf of EP-Europace, UK)}

\begin{abstract}
${ }^{1}$ Cardiology, Bern University Hospital, 3010 Bern, Switzerland; ${ }^{2}$ Department of Cardiology, Maastricht University Medical Center, 6281 Maastricht, The Netherlands; ${ }^{3}$ Isar Medical Centre, 80331 Munich, Germany; ${ }^{4}$ Cardiovascular Center Frankfurt, 60389 Frankfurt, Germany; ${ }^{5}$ Cardiac Arrhythmia Research Center, Centro Cardiologico Monzino, IRCCS, 20138 Milan, Italy; and ${ }^{6}$ Davidai Arrhythmia Center, Sheba Medical Center, 52621 Tel Hashomer, Israel
\end{abstract}

\section{Introduction}

Atrial fibrillation (AF) is the most common clinically relevant cardiac arrhythmia. The estimated prevalence in the general population is $1-2 \%$ and increases with age. ${ }^{1-8}$

Patients with AF are at increased risk of thromboembolism, in particular ischaemic stroke. The risk of stroke in patients with nonvalvular (essentially non-rheumatic) AF is 5\% per year. ${ }^{9}$ Moreover, strokes related to AF are associated with a higher mortality and morbidity when compared with non-AF strokes, emphasizing the need for more effective stroke prevention in these patients. ${ }^{10}$

The $\mathrm{CHADS}_{2}$ score (cardiac failure, hypertension, age, diabetes, stroke counted double) was established to assess the risk of thromboembolic events in patients with AF of non-valvular origin. ${ }^{11}$ Although there is a clear relationship between the $\mathrm{CHADS}_{2}$ score and stroke rate, the $\mathrm{CHA}_{2} \mathrm{DS}_{2}$-VASc score has recently been introduced and adopted by the European Society of Cardiology (ESC) as well as by American Heart Association, American College of Cardiology, and Heart Rhythm Society and other national bodies' guidelines for AF in an attempt to improve risk stratification in the low-risk group by considering additional stroke risk factors (gender, vascular disease) in addition to old factors including cardiac failure, hypertension, age (divided to two risk classes) diabetes, and stroke that may influence a decision for anticoagulation therapy. ${ }^{12}$

Prospective and randomized studies show that oral anticoagulation (OAC) significantly reduces the risk of thromboembolism. ${ }^{13}$ However, this treatment is underutilized in patients with AF due to poor patient compliance, contraindications, and potential bleeding complications. $^{14-18}$
The pathogenesis of thrombogenesis in AF is multifactorial and includes the Virchow triad of events leading to thrombus formation, i.e. endothelial or endocardial damage or dysfunction, abnormal blood stasis, and altered haemostasis, platelet function, and fibrinolysis. ${ }^{19}$

There is evidence for endothelial damage, as well as intense fibrosis and inflammation in the left atrium (LA) in patients with $A F{ }^{20}$ These changes are especially prominent in the left atrial appendage (LAA), a particularly low flow area, and may enhance to thrombus formation by their effect on the endocardial surface. ${ }^{21,22}$

There is also strong evidence for the presence of a prothrombotic and hypercoagulable state in AF, as manifested by increased blood levels of markers reflecting coagulation activity (prothrombin fragments 1 and 2 , fibrinopeptide A, thrombin-antithrombin complexes, and $\mathrm{D}$ dimer). ${ }^{23,24}$

The LAA is the remnant of the embryonic LA. The LAA is a tubular blind-ended structure with different lobes and variable morphology. Its complex structure with areas of relative low flow predisposes to stasis, especially during AF when blood flow velocity decreases, as can be visualized on transoesophageal echocardiography (TOE) examination with spontaneous contrast (smoke) or on pulsed-wave Doppler during paroxysms of $A F^{25-28}$ It has been shown that in patients with non-valvular AF, 90\% of thrombi are located in the LAA. ${ }^{29}$ Thrombi detected in the LAA as well as a reduced LAA peak flow velocity were identified as independent predictors of an increased thromboembolic risk, ${ }^{30,31}$ and also for recurrence of stroke among non-valvular AF patients recovering from ischaemic stroke. ${ }^{32}$

Moreover, patients with certain LAA morphologies have been shown to have different levels of thrombo-embolic risk further supporting the role of LAA in embolization. ${ }^{33}$

\footnotetext{
* Corresponding author. Tel: +972 52 6667128. E-mail address: michael.Glikson@sheba.health.gov.il

Document is endorsed by the European Heart Rhythm Association (EHRA) and the European Association of Percutaneous Cardiovascular Interventions (EAPCI). Developed in partnership with EHRA and EAPCl.

The article has been co-published with permission in EP-Europace, HeartRhythm and Eurointervention. All rights reserved in respect of Eurointervention. C) The Authors 2014. For EP-Europace, (C) The Author 2014.
} 
Left atrial appendage occlusion or exclusion in $\mathrm{AF}^{34-50}$ is based on the concept that only $\sim 10 \%$ of clinically relevant emboli in non-valvular AF do not originate in the LAA. ${ }^{51-61}$ The rationale is that, after excluding the LAA as an embolic source, the remaining small risk does not longer warrant OAC with its inherent risk for major bleeds. The risk of embolism from the LAA or the LA increases with age, but so does the risk of bleeding under OAC. Various surgical and catheter-based methods have been developed to exclude the LAA and the success of catheter-based methods attests to the validity of this concept. ${ }^{62}$ This document reviews the catheter-based methods and their results.

\section{History}

\section{Surgical techniques for left atrial appendage exclusion}

Incidental surgical LAA exclusions during heart surgery have been performed for decades. ${ }^{63}$ A first report by Madden dates back to 1949. ${ }^{34}$ The popularity of this procedure remained low as it did prolong the surgical procedure and required some specific techniques. Moreover, follow-up TOE often detected residual flow in the LAA in case of a simple suture ${ }^{64}$ and in a large number of these patients the need for lifelong $O A C$ with a vitamin $K$ antagonist (VKA) remained due to indications unrelated to $A F$, most commonly mechanical valve prostheses in the mitral position. An electrocardiographically guided thoracoscopic technique for isolated surgical LAA occlusion $^{65}$ and a percutaneous endocardial/epicardial approach (Lariat, SentreHeart) $^{46,47,50}$ where an epicardial sling suture is guided by a magnet inside the LAA have been introduced more recently. In addition, a number of other minimally invasive surgical and percutaneous devices including the AtriClip, Cardioablate, and Aegis, are at various stages of advanced animal studies or first in man experiments.

\section{Catheter-based left atrial appendage occlusion}

The electrophysiologist Michael Lesh conceived a device called PLAATO (Percutaneous Left Atrial Appendage Transcatheter Occlusion) for percutaneous plugging of the LAA, intrigued by the fact that during ablation of AF the LAA was easily accessible. He assisted Horst Sievert's first such intervention on 30 August $2001 .^{38}$ The PLAATO device (Medtronic) had a number of significant drawbacks and the implantation technique was fairly difficult and perilous. The device was pulled off the market although clinical results were favourable. ${ }^{43}$

On 15 June 2002, percutaneous LAA occlusion without general anaesthesia or echocardiographic guidance in awake patients was introduced by Bernhard Meier using the technically simpler Amplatzer approach ${ }^{41}$ and taking advantage of the double-disc devices routinely used for occlusion of an atrial septal defect (ASD) or a patent foramen ovale (PFO). The disc destined for the right side of the interatrial septum in ASD or PFO occlusion covered the entrance of the LAA not unlike the plate of a pacifier outside a toddler's mouth (pacifier principle). Subsequently, the Amplatzer devices and introducer sheaths (St Jude) were adapted for LAA occlusion. The dedicated Amplatzer Cardiac Plug (ACP) and LAA sheath were introduced in 2008.
On 12 August 2002, the Watchman device (Boston Scientific) was introduced into clinical practice by Eugen Hauptmann and Eberhard Grube. It has since undergone several modifications and is approved in many countries worldwide. It remains the only device studied in randomized trials, such as PROTECT $\mathrm{AF}^{45}$ and the PREVAIL. ${ }^{66}$ In December 2013, an Food and Drug Administration (FDA) advisory committee voted favourably for approval of this device for use in the USA as an alternative to warfarin.

The WaveCrest device (Johnson and Johnson) has recently received CE mark, as well. It was developed with separately applicable fixation anchors and a different design intended to provide more superficial deployment at the entrance to LAA with little or no manipulation within the LAA body.

Since 2010, a percutaneously inserted intra-LAA patch has been used by a group around Eleftherios Sideris. ${ }^{49}$ Other devices, currently in early animal or human trials, have been developed by, Occlutech, Gore, and Lifetech.

The feasibility of the mentioned Lariat non-surgical combined endocardial/epicardial suture ligation of the LAA was first demonstrated in animals by Lee et al. in $2010,{ }^{46}$ then in humans by Bartus et $a .^{47}$ in 2011 , and subsequently evaluated in clinical routine. The device has CE mark and is approved by the FDA.

\section{Currently available devices and techniques including some surgical techniques}

A variety of surgical approaches have been examined mainly in observational studies and with mixed results. ${ }^{37,40,42,64,67}$ Two alternative concepts to achieve LAA occlusion are obstruction of the LAA orifice with an occlusion device ${ }^{41,45,48,68}$ or percutaneous suture ligation using an endocardial/epicardial approach. ${ }^{47}$

Currently, three entirely catheter-based devices are commercially used for mechanical orifice obstruction, the Watchman and WaveCrest devices and the ACP. The Lariat device is used for percutaneous endocardial/epicardial suture ligation. ${ }^{46,47,50}$ They all have obtained CE mark.

The Watchman device consists of a nitinol cage (Figure 1) with a $160 \mu \mathrm{m}$ polyethylene terephthalate(PTFE) membrane covering the surface facing the LA. Fixation barbs are attached to the portion facing the circumference of the appendage minimizing the risk of dislodgement and embolization. It is attached to a delivery cable and delivered via a 14 French ( $F$, outer diameter $4.7 \mathrm{~mm}$ ) access sheath. A single curve or double curve configuration sheath can be used depending on the appendage orientation. After transseptal puncture (a low posterior puncture location is preferred to allow coaxial alignment with the appendage), intravenous heparin is administered maintaining an activated clotting time (ACT) $>250 \mathrm{~s}$ and a pigtail catheter is positioned into the LAA over a soft J-tipped 0.035 inch wire. Angiography of the LA focusing on the LAA is performed in several views [right anterior oblique (RAO) caudal and cranial projections typically outline the LAA best], delineating shape and size. Sizing of the device, taking advantage of both cine angiography and TOE, is discussed under the 'Imaging for left atrial appendage occlusion' section. The device size is typically chosen $10-20 \%$ larger than the diameter of the landing zone (measured from the area of the left circumflex 
coronary artery across the LAA to $\sim 1 \mathrm{~cm}$ inward from the tip of the ridge separating LAA and left upper pulmonary vein). Subsequently, an extra-stiff J tipped 0.035 inch wire is advanced into the distal LAA and the pigtail catheter and transseptal sheath are exchanged for the access sheath while maintaining wire position. Some operators introduce a catheter into the left upper pulmonary vein first instead of aiming at the LAA. In this case, after transseptal puncture, an extrastiff 0.035 inch wire is positioned into the left upper pulmonary vein and the transseptal sheath is exchanged over the wire for the access catheter. Subsequently, a pigtail catheter is advanced

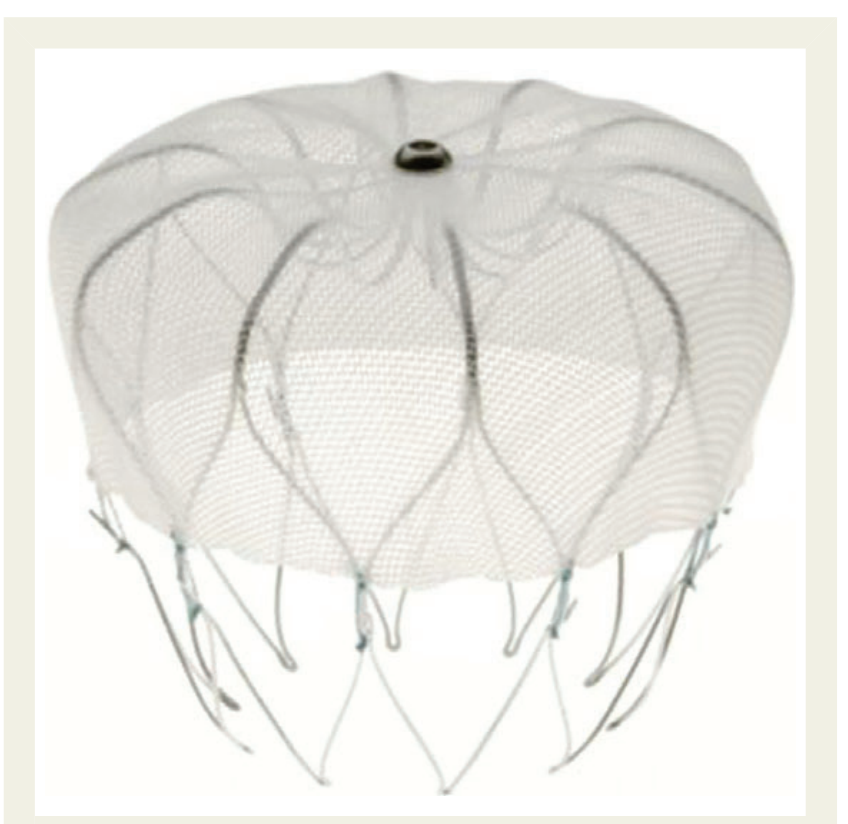

Figure I Watchman LAA occlusion device. through the access sheath to the LAA. The access sheath has three markers corresponding to device size and is advanced into the LAA until the marker aligns with the ostial plane of the appendage. After purging, the device is advanced via a delivery catheter to the distal end of the access sheath. Finally, the access sheath and delivery catheter are slowly withdrawn while maintaining device position, allowing it to unfold. Once deployed, appropriate position is confirmed by both angiography and TOE. A tug test is performed under fluoroscopy or TOE demonstrating simultaneous movement of the device and appendage. Optimally, the device should not protrude $>4-7 \mathrm{~mm}$ beyond the LAA ostium (depending on device size outlined in the manufacturer's instructions for use manual) and should cover the entire ostium with no or minimal ( $<5 \mathrm{~mm}$ by colour Doppler) residual flow and a compression grade of $8-20 \%$ (some recommend a higher compression grade of $15-30 \%$ ). The compression grade is expressed in per cent comparing the diameter of the implanted device with the unconstricted diameter indicated by the manufacturer in the size label. When optimal positioning is confirmed, the device is released. If position or size appears suboptimal, the device can be retrieved and exchanged or repositioned. Table 1 lists the basic steps of LAA device implantation.

The Amplatzer ACP consists of a cylindrical nitinol cage (lobe) securing the device in the LAA body connected by a short flexible waist to a nitinol plate (disc) covering the appendage ostium. Both are laid in with polyester fabric (Figure 2). Similar to the Watchman device, the cage is surrounded by fixation hooks. The flexible waist facilitates positioning and conformation to variable and complex appendage shapes. Of note, contrary to the Watchman device, the length of the ACP is shorter than its diameter. Therefore, whereas the Watchman device cannot be implanted in appendages shorter than wide, the ACP may be an option under those circumstances. In fact, ACP implantation can be attempted in virtually all appendages. The more recently introduced Amulet generation of that device may

\section{Table I Step-by-step device implantation}

Transoesophageal or intracardiac echocardiography immediately prior to the procedure to rule out LAA thrombus (contraindication for the procedure)

(1) Femoral venous access

(2) Transseptal puncture (typically in an inferoposterior location)

Heparin via the sheath or intravenously with maintenance of a goal ACT of $>250 \mathrm{~s}$ (some prefer heparin administration prior to transseptal puncture)

(3) Sheath access to the LAA (either option a or b)

(a) A pigtail catheter is advanced into the LAA (and angiography performed) and subsequently exchanged over a stiff guidewire for the delivery sheath

(b) A catheter (typically a multipurpose catheter) is advanced into the left upper pulmonary vein, and exchanged over a stiff guidewire for the delivery sheath. A pigtail catheter is advanced via the delivery sheath into the LAA (and angiography performed) and subsequently the delivery sheath is advanced over the pigtail catheter into the LAA

(4) LAA measurements are made and the appropriate device size is chosen (10-20\% larger than the landing zone diameter)

(5) The sheath is advanced over a stiff guidewire (in case of option 3a) or the pigtail catheter (in case of option 3b) until the proximal marker corresponding with the device size matches the LAA ostium

(6) The stiff guidewire (in case of option 3a) or pigtail catheter (in case of option 3b) is removed

(7) Blood is allowed to exit the sheath while holding the sheath hub and flush line as low as possible (below the patient's anticipated midline of the chest) to eliminate any air trapped in the sheath

(8) Device preparation (generous flushing of the device within the delivery catheter)

(9) The delivery catheter and device are advanced until the distal marker of the delivery catheter and delivery sheath match

(10) The sheath is gradually pulled back as a unit while maintaining delivery cable position to allow the device to unfold

(11) Position is confirmed via echocardiography and fluoroscopy and a tug test is performed

(12) Device release (e.g. delivery cable turned counter clockwise) 


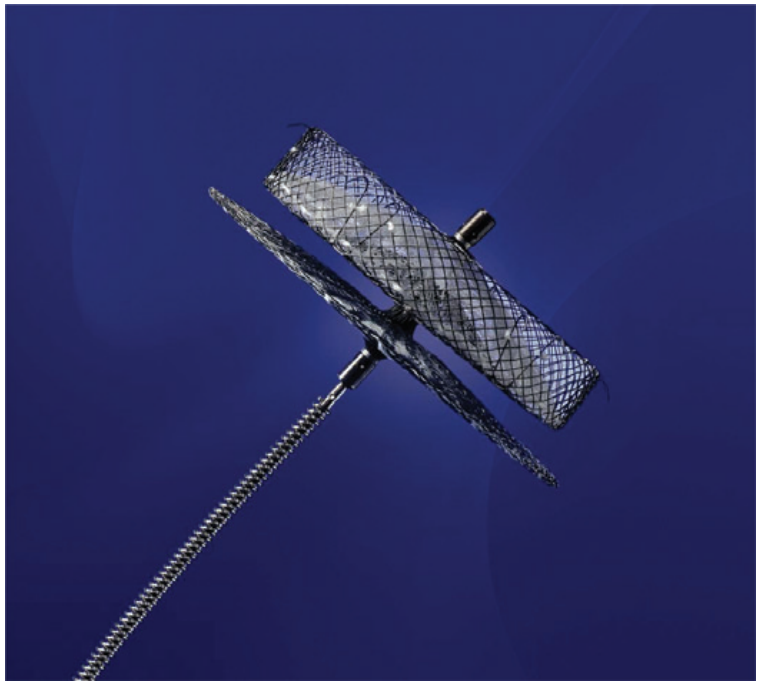

Figure 2 Amplatzer Cardiac Plug.

improve ease and safety of use and further expands the size range of appendages that can fit the device. ${ }^{69}$ It also has dimensional changes that are intended to improve stability and occlusion of the LAA os by the disc. The device fits landing zones from 11 to $31 \mathrm{~mm}$. Femoral venous access (sheath sizes 9-14 F inner diameter depending on the device size and type), transseptal puncture, LAA angiography, and TOE imaging as well as delivery sheath positioning are as previously outlined (Table 1). The sheath may alternatively be directly advanced into the LAA. Like the Watchman device, the ACP is retrievable prior to disconnection from the pusher cable. With the delivery sheath at least $15 \mathrm{~mm}$ inside the LAA, the first half of the device (lobe) is delivered by sheath retraction and the second half by pushing it out. Then, the disc is produced by further retracting the sheath while still gently pushing on the device. With optimal positioning, the lobe should be visibly compressed (tire shape) with an appreciable distance to the disc, connected by a stretchable waist. The disc should assume a slightly concave shape and cover the entire LAA ostium or at least most of it (pacifier principle). After a sustained tug test and confirmation of an optimal position, the ACP is released.

The WaveCrest device consists of a nitinol structure without exposed metal hub and with a foam layer facing the LAA to promote rapid organization and a PTFE layer facing the LA to reduce thrombus formation (Figure 3). It is conformable to LAA anatomy and fixation anchors are separately actionable and radially positioned to provide effective fixation at the appendage once the desired position in attained. The WaveCrest delivery sheath is designed to optionally position the occluder in the LAA ostium during deployment and anchoring. Of note, the delivery sheath is not intended for deep access and manipulation inside the appendage as the device is designed and intended for proximal placement. Should the Watchman or the ACP devices be deemed too large for very short appendages, the WaveCrest may provide an alternative. As previously described for the Watchman and ACP devices (Table 1), LA access is provided by a $12 \mathrm{~F}$ sheath in the femoral vein and a preferably posterior transseptal puncture. The measurements

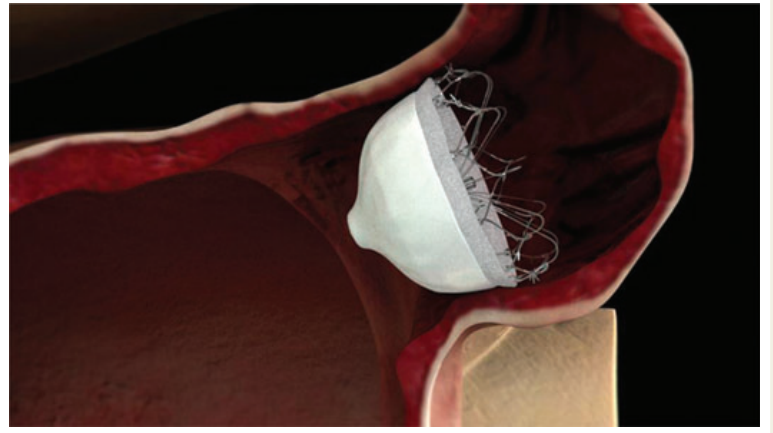

Figure 3 WaveCrest device.

of the projected landing zone on TOE include the distance from the left circumflex coronary artery to $10 \mathrm{~mm}$ distal to the apex of the lateral ridge (coumadin ridge). Most importantly, measurements should include the widest part of the ostium, since the positioning has to be in the proximal end of the LAA mouth, allowing headroom for anchors. Measurement at $0^{\circ}, 45^{\circ}, 90^{\circ}$, and $135^{\circ}$ are recommended to capture the long axis and short axis of the ostium and the $135^{\circ}$ view usually shows the widest diameter. The more proximal positioning of the WaveCrest device is related to the concept that distal deployment may compress the device itself and the anchors. Over-compressed anchors may become entangled. Therefore, a position proximal to all lobes guarantees best occlusion and the risk of pericardial effusion is minimized. Before detaching the device, the sheath needs to be pulled back $\sim 2 \mathrm{~cm}$ from the occluder and contrast medium is injected through the delivery system port to visualize the distal LAA. A tug on the delivery catheter is performed until movement is seen (device and tissue move as a unit). In case repositioning appears necessary, the hooks are withdrawn before moving the device. After these steps, the device is set free.

The endocardial/epicardial Lariat approach to LAA occlusion leaving no foreign material in the heart is more complicated. A lassolike suture, (snare), is positioned by a percutaneous technique epicardially at the base of the LAA and tightened followed by suture ligation. First, epicardial access is obtained similar to epicardial access for electrophysiological ablations ${ }^{70}$ and an epicardial soft tipped $14 \mathrm{~F}$ access cannula inserted into the pericardial space. Secondly, femoral venous access is established and transseptal puncture performed. Via an 8.5 F delivery sheath (e.g. SL 1 transseptal catheter by St Jude), a specially designed magnet tipped 0.025 inch endocardial guide wire is advanced into the LAA apex followed by a balloon mounted (compliant $20 \mathrm{~mm}$ balloon) catheter. The position of the endocardial guide wire is confirmed via contrast medium injection through the balloon catheter lumen. Via the percutaneous epicardial access sheath, a second 0.035 inch magnet tipped epicardial wire is advanced towards the LAA and aligned with a magnet located at the distal end of the endocardial wire already located in the LAA apex. The balloon in the LAA is inflated to help identify the appendage ostium and allow a lasso delivered via the epicardial sheath over the epicardial wire to grab the LAA ostium. Finally, the lasso is tightened. Appendage occlusion is confirmed by TOE and fluoroscopic imaging and a suture is deployed. The epicardial and endocardial delivery systems are 


\section{Table 2 Tips and tricks for LAA device implantation}

(1) Using a PFO for transseptal access may lead to suboptimal delivery sheath alignment with the LAA. Sometimes this problem can be solved by custom shaping the sheath with or without hot air gun

(2) Minimize device sheath time in the LA especially in large LA with LAA sludge and/or pronounced smoke (longer indwelling gear time increases device-associated thrombus risk)

(3) Minimize the risk of air embolism

(a) Generously backbleed the transseptal and access/delivery sheath allowing air to exit the sheath prior to inserting any equipment or devices (keep the haemostatic valve and device arm below the midline of the chest). Keeping the haemostatic valve, proximal sheath end, and side arm under water may prevent air entering the system during backbleeding

(b) Remove dilators, catheters, and transseptal puncture needles slowly

(c) Flush the device and delivery catheter generously prior to insertion

(4) Choosing a device

(a) Avoid implanting a Watchman device if the LAA length is less than the device diameter

(b) Avoid implanting a Watchman device if the LAA diameter is $<17$ or $>30 \mathrm{~mm}$

(c) Avoid implanting an ACP if the landing zone diameter is $>29 \mathrm{~mm}$ (31 for Amulet)

(d) Avoid implanting an ACP if the LAA length is $<10 \mathrm{~mm}$ ( 7.5 for Amulet)

(e) If the LAA is too large for either the Watchman or ACP (but the maximal diameter $<40 \mathrm{~mm}$ ), suture occlusion with the Lariat technique could be considered

(f) Avoid Lariat suture ligation in patients with a superiorly oriented LAA or in LAAs that course behind the pulmonary artery (removal of the Lariat loop may be challenging or impossible). Use of the Lariat is contraindicated in patients with prior heart surgery (due to pericardial adhesions) and may be exceedingly difficult or impossible in patients with pectus excavatum

(5) Confirm adequate position

Watchman

(a) The shoulder should not protrude beyond the LAA ostium by $>20 \%$ of its diameter ( $<4.2 \mathrm{~mm}$ for a $21 \mathrm{~mm}$ device, $<4.8 \mathrm{~mm}$ for a $24 \mathrm{~mm}$ device, $<5.4 \mathrm{~mm}$ for a $27 \mathrm{~mm}$ device, $<6 \mathrm{~mm}$ for a $30 \mathrm{~mm}$ device, and $<6.6 \mathrm{~mm}$ for a $33 \mathrm{~mm}$ device)

(b) Assure optimal compression (10-20\%) by both TOE and fluoroscopy

(c) Do not accept residual leaks of $>3 \mathrm{~mm}$

(d) Look in all standard TOE views (see above)

ACP

(a) Assure slightly concave disc shape

(b) Optimally, the lobe should be slightly compressed (tyre-shaped), no compression or deformity suggests a too small size or too proximal position, whereas too much compression with significant alteration of the shape suggests too large size or too distal positioning

(c) The lobe should not protrude more than one-third beyond the left circumflex coronary artery

(d) Optimally, the disc and lobe should be separated slightly

(e) Look in all standard TOE views $\left(0^{\circ}, 30^{\circ}, 45^{\circ}, 90^{\circ}\right.$, and $135^{\circ}$ for adequate seal and coverage of all lobes)

ACP, Amplatzer Cardiac Plug; LA, left atrium; LAA, left atrial appendage; TOE, transoesophageal echocardiography

removed. Subsequent necrosis of the strangulated LAA is likely but apparently not a problem.

Table 2 provides tips and tricks for use during implantation of intravascular LAA occluders.

\section{Imaging for left atrial appendage occlusion}

Adequate implementation of various imaging modalities is essential for developing a successful LAA occlusion programme. Imaging is important for pre-procedural and periprocedural assessment of the LAA and for follow-up. The LAA can occasionally be visualized with transthoracic echocardiography (TTE) but usually requires TOE, intracardiac echocardiography (ICE), cardiac magnetic resonance imaging (MRI), or computerized tomography (CT). Transoesophageal echocardiography is an integral part for guidance in most but not all ${ }^{41}$ LAA occlusion publications. Imaging modalities continue to evolve. The value of newer modalities should be compared against TOE, the gold standard for imaging the LAA and guiding LAA occlusion procedures.

\section{Pre-procedural assessment}

It is important to confirm the absence of LAA thrombi prior to LAA occlusion. The presence of mobile thrombi is a contraindication for percutaneous LAA occlusion, since dislodgement of thrombus may occur with manipulation of sheaths or devices in the LAA. Currently, TOE is considered the reference technique for the detection of thrombi in the LAA. ${ }^{71}$ In most patients, the LAA can be adequately visualized using TOE. Yet, in some patients there may be difficulties in obtaining unequivocal images, as for example, in patients with prominent pectinate muscles which may be falsely interpreted as LAA thrombus. The incidence of LAA thrombus on TOE among patients undergoing AF ablation who have been adequately anticoagulated was found to be very low and in those patients an elevated $\mathrm{CHADS}_{2}$ score was the strongest predictor of LAA thrombus. ${ }^{72}$ The prevalence of LA or LAA thrombus or sludge (dynamic gelatinous, precipitous echodensity without a discrete mass) in patients undergoing TOE examination for pulmonary vein isolation increased from $0 \%$ in patients with $\mathrm{CHADS}_{2}$ score of $0-11 \%$ in patients with $\mathrm{CHADS}_{2}$ score of $4-6 .{ }^{72}$ Of note, the prevalence of LAA thrombus may be higher in patients scheduled for LAA occlusion, since patients 
may not be anticoagulated because of previous bleeding complications. The diagnostic performance of a dual-enhanced cardiac CT protocol for detection of LAA thrombi was studied in patients with stroke. ${ }^{73-76}$ The overall sensitivity and specificity of CT for the detection of thrombi in the LAA were 96 and $100 \%$, respectively. ${ }^{74}$ The role of cardiac MRI in management pathways for diagnosing LAA thrombus ${ }^{77}$ is not well enough defined and further studies are required. Ad hoc LAA occlusion using LA angiography for thrombus exclusion has been described in a small series. ${ }^{78}$

Pre-procedural TOE already hints to the device size or should reveal if the LAA appears difficult or impossible to occlude. The LAA is best imaged from the mid-oesophageal view. Using the multiplane function, the LAA is interrogated in multiple views $\left(0^{\circ}, 45^{\circ}, 90^{\circ}\right.$, and $\left.135^{\circ}\right)$. The morphology and presence of multiple lobes of the LAA are usually only appreciated at an angle beyond $100^{\circ}$. Characterization of the LAA shape and the presence of multiple lobes can be facilitated by threedimensional (3D) TOE or pre-procedural MRI or CT.

Watchman and ACP devices require specific TOE measurements necessary for choosing the appropriate device sizes. The maximal width of the LAA ostium and depth of the LAA are first measured (Figure 4). The maximum LAA ostium width is measured from the level of the left circumflex coronary artery to a point $1-2 \mathrm{~cm}$ from the tip of the left superior pulmonary vein limbus (at $0^{\circ}$ ) and from the mitral annulus to a point $1-2 \mathrm{~cm}$ from the limbus $\left(45^{\circ}, 90^{\circ}\right.$, and $135^{\circ}$ ). The ostium of the LAA usually has an oval shape. It is recommended to use the diameter of the longest axis (generally superoinferior). The depth of the LAA is measured from the ostium line to the apex of the LAA. The Watchman device can be used if the maximum LAA ostium is $>17$ or $<31 \mathrm{~mm}$, the ACP if it is $<28 \mathrm{~mm}$ (for larger diameters, deeper placement may be an alternative or the new Amulet device may be used for landing zones up to $31 \mathrm{~mm}$ ). For both, the Watchman and ACP devices, sizing tables are available. In general, the device size should at least be 10-20\% larger than the measured diameter, although some operators may prefer up to $30 \%$. If the depth of the LAA is smaller than the width of the ostium, placement of a Watchman device may result in unstable position with unacceptable device protrusion into the LA. For further information

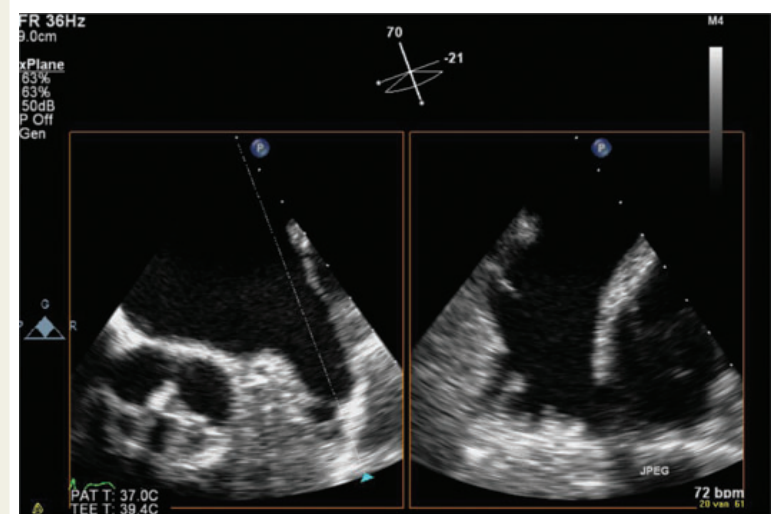

Figure 4 Three-dimensional TOE with live $x$-plane imaging allows simultaneous display of the LAA from two views. Measurement of LAA ostium diameter $(A)$ and LAA depth $(B)$ is crucial for selecting the appropriate device size. regarding the sizes and choice of the device, refer to the section Implantation techniques and to Table 2.

\section{Procedural imaging to guide left atrial appendage occlusion}

Real-time visualization of the LAA for device positioning and deployment is a key for successful implantation. As long as the total procedure time can be kept short, deep sedation may not be necessary. However, the majority of centres perform the procedure in general anaesthesia with 2D TOE in combination with $X$-ray guidance, while some operators close LAAs under fluoroscopic guidance alone to facilitate the logistics (less personnel and no sedation or intubation required). ${ }^{41,78,79}$ Personnel performing TOE during LAA occlusion should be well trained and familiar with the procedure and the required measurements for the type of device used. Limited data are available on LAA occlusion using ICE, but this may allow the procedure to be performed under local anaesthesia. ${ }^{80}$ Reports showed superior visualization of the LAA with the ICE probe positioned in the LA or pulmonary artery compared with a position in the right atrium or coronary sinus. To place the ICE probe in the LA in the absence of a PFO, a second transseptal passage is required. Left atrial appendage occlusion with ICE should only be performed by operators with experience in ICE catheter handling and interpretation of ICE images.

Only 3D TOE can provide a real-time full view of the LAA and importantly, the shape of the LAA ostium. A recent report demonstrated that 3D TOE-derived measurements of LAA orifice area were closely related with CT measurements. In this study, 2D TOE significantly underestimated LAA dimension and orifice size, as compared with 3D TOE. ${ }^{81}$ Future studies demonstrating the feasibility and accuracy of 3D TOE during LAA occlusion procedures are required.

Transoesophageal echocardiography or ICE also facilitate transseptal puncture. Most operators prefer an inferoposterior, others a mid to superior and posterior puncture. This illustrates how variable the anatomy is. A puncture site superior and anterior is usually suboptimal. Therefore, LA access via a PFO (which results in a superior and anterior path) is avoided by most operators. After positioning a sheath or pigtail catheter in the LAA, selective contrast injection under fluoroscopy in RAO caudal and cranial $\left(10^{\circ}-30^{\circ}\right)$ projection gives excellent views of the LAA not overlapping the LA. Final decision on device size is based on information collected with both echocardiography and fluoroscopy. Real-time TOE provides direct information on the position of the delivery sheath in the LAA and helps during device deployment. Following successful device deployment, the pericardium is evaluated for effusion. Some experts recommend another echocardiography (TTE usually) to confirm device position and exclude pericardial effusion prior to discharge. We are not aware of any information on the yield of such an examination. Rare device embolizations upon first mobilization of the patient with change of the heart position have been observed.

\section{Follow-up imaging}

Transoesophageal echocardiography is the most revealing technique. Alternatively, post-procedural imaging to assess device position, peridevice residual flow in the LAA, and thrombus formation on the device consists of chest X-ray (position only) or CT. Magnetic 
resonance imaging is hampered by device artefacts. The timing of a follow-up TOE varies between institutions. Most operators use early or follow-up echocardiographic findings, i.e. the absence of large residual flow into the LAA or thrombus, as a guide for prescribing antithrombotic drugs. In the PROTECTAF (Watchman Left Atrial Appendage System for Embolic Protection in Patients with Atrial Fibrillation) trial, serial TOE imaging was performed at 45 days, 6 months, and 1 year following implant. ${ }^{45}$ The logic behind the timing of the first two examinations was based on changes in medications subsequent to the examination, i.e. warfarin and clopidogrel were discontinued if TOE showed the absence of thrombus, occlusion of the LAA, or residual peridevice flow of $<5 \mathrm{~mm}$ width (assessed by colour Doppler) at 45 days and 6 months. A sizable series with the ACP used a regimen of clopidogrel for 1 and acetylsalicylic acid (ASA) for 3 to 6 months. ${ }^{82}$ Follow-up TOE was performed at variable times between 3 and 6 months following implantation.

For patients treated with coumadin and antiaggregants according to the PROTECT AF protocol, it is prudent to follow the imaging protocol of the trial, as it serves as a guide to changes in medications. In other patients who are treated with antiaggregants only, it makes sense to image prior to cessation of clopidogrel and again if ASA cessation is planned. It is recommended to perform a TOE at 45 days to 6 months after implantation, since most adverse events including device dislodgement and thrombi were so far documented at the 45-day TOE. The value of additional TOE investigations at later time points is unclear. In case of a new embolic event, a repeat TOE is indicated as is the case if a TOE demonstrated a significant leak or a thrombus on the device (see chapter on Anticoagulation).

Residual peridevice flow is a common echocardiographic finding in patients treated with the Watchman device. There is concern that this could potentially lead to thrombo-embolic events, since new thrombi may form in the distal LAA pouch as a result of low flow velocities. In $41 \%$ of patients of the PROTECT AF study, this was observed during TOE at 45 days. ${ }^{83}$ This decreased to $32 \%$ at the 1-year follow-up. The majority of patients had flow jet widths of 1-3 mm. Of note, in patients with peridevice flow who discontinued warfarin, the clinical outcome was not affected. Amplatzer devices have less residual flow because the disc of the device typically covers the entire LAA ostium (pacifier principle). For further recommendations on antithrombotic treatment in patients with peridevice flow, we refer to the section on Anticoagulation.

Information is scarce about the role of imaging in Lariat device implantation and follow-up. Transoesophageal echocardiography is used to verify LAA occlusion during the procedure and for follow-up, but no clear protocol has been put forward.

\section{Suggested standards for operators and centres and required information for registries and studies}

\section{Requirements for operator and centres Training and knowledge of physicians performing the procedure}

Extensive knowledge of cardiac anatomy, particularly of the LA and LAA and the surrounding structures is required for operators who embark on LAA occlusion. Operators must be acquainted with transseptal puncture techniques and with pericardiocentesis as a prerequisite to start LAA occlusion training. Experience with other procedures performed transseptally for an interventional cardiologist or with LA ablation procedures for an electrophysiologist should be required to be sufficiently cognizant of LA anatomy and the anatomical position of LAA in relation to the surrounding structures. ${ }^{84-86}$ Operators must be aware of the several LAA anatomical variations, in terms of size, angulation, and mobility. The procedural skill is also based upon the operator's ability to put LAA morphology in relation to the technique and the outcome of the procedure. Left atrial appendage anatomy plays a key role for the selection of the most adequate occlusion device. The success of the procedure is closely related to the level of knowledge and experience of each individual belonging to the team, including the echocardiographer supporting the procedure. The learning curve has to be expected rather flat in light of the intricacy of the procedure.

A key factor for procedural success is a structured training process before becoming an independent operator. The training process, currently provided by the device manufacturer, includes basic principles, specific device features, and the performance of the procedure. We believe that a training process for implantation of a specific device should include the following:

(1) Theoretical course, often taken on line, teaching anatomy, clinical data, and the theory of device implantation including interactive cases. This training stage should also include critical issues, such as patient and device selection, possible complications, and detection and management of major adverse events including pericardiocentesis.

(2) Practical training including bench training with handling of the equipment, and attending live cases at experienced centres, or interactive during congresses or online. The addition of hands-on simulator training on several virtual cases is helpful but should not replace attendance at real cases.

(3) During their first procedures, operators are to be properly proctored at their sites by experienced operators.

Importantly, in addition to the implanters, echocardiographers involved in patient evaluation for the procedure and echocardiographic support during procedures should be specifically trained for the respective aspects of the procedure.

\section{Centre and laboratory requirements}

Since the procedure is usually performed under general anaesthesia and TOE guidance, an anaesthesiologist and an experienced echocardiographer who had specific training in supporting LAA occlusion procedures should be part of the procedural team. Nursing and technical personnel should also be familiar with every procedural step, well accustomed to interventional techniques, and prepared to manage adverse events and emergency situations. Site readiness for the procedure necessitates not only a knowledgeable operator but a thorough team understanding of the procedure and of the individual role of each member of the team. According to current practice in house cardiovascular surgery in centres performing LAA occlusion procedures is not deemed mandatory but arrangements for rapid transfer to a centre with available cardiac surgery should be available, with a maximum time of $60 \mathrm{~min}$ to reach the operating room. 


\section{Data collection for registries and studies}

In light of the worldwide increasing number of LAA occlusion procedures, there is a need to collect extensive information regarding the number of procedures, criteria of patient selection, acute and longterm clinical outcome, and the occurrence of any type of complications. $^{87}$ Initial clinical data are available from the PROTECT AF ${ }^{45}$ study and Continued Access Protocol (CAP) study analysis ${ }^{88,89}$ using the Watchman device. They are, in part, offering randomized comparisons to warfarin, whereas data about success and complications rates with the ACP device are entirely based on registries with indirect comparison to $\mathrm{OAC} .{ }^{90}$ Due to the fact that not all patients with $A F$ and contraindications to $O A C$ or with serious untoward effects with OAC are suitable for LAA occlusion, there is a need for extensive data to guide patient selection. In this regard, studies should be including multiple centres with proven experience of each operator with at least 10 proctored and 10 main operator procedures. While new studies are being designed, there is also a need for large registries of LAA occlusion. To create large registries, defined inclusion criteria among the different centres (e.g. $\mathrm{CHA}_{2} \mathrm{DS}_{2}$ VASC and HAS-BLED scores) are the basis. This allows assessment of acute and long-term clinical outcome with respect to several issues, such as successful implantation, periprocedural or late complications, rate of neurological cardiovascular events, and safety of the approach. For the purpose of uniformity and ability to compare and group together results of different registries and studies, Table 3 lists recommended parameters to be collected in LAA occlusion registries.

\section{Clinical results}

\section{PLAATO}

Several observational human studies using the no longer available PLAATO device have been published. ${ }^{38,43,91-93}$ In all reports, antiplatelet therapy only was used after implantation. Invariably, the postprocedural stroke incidence was lower than projected by the $\mathrm{CHADS}_{2}$ score for patients treated with ASA only. According to data from three studies including a total of 359 patients (mean follow-up of 9.6 months, 9.8 months, and 24 months, respectively), the annualized stroke risks were $2.3,2.2$, and $0.7 \%$, respectively, substantially lower than the risks predicted based on the $\mathrm{CHADS}_{2}$ score $(6.6,6.3$, and $4.9 \%$, respectively). ${ }^{43,92,93}$ At long-term follow-up (61 patients, mean follow-up of 5 years), the annual stroke or transient ischaemic attack rate $(3.8 \%)$ remained lower than predicted by the $\mathrm{CHADS}_{2}$ score (6.6\%). ${ }^{92}$ Including data from 364 patients (three studies) with attempted or successful PLAATO implantation, procedural mortality and the incidence of pericardial effusion requiring drainage, device embolization, and periprocedural stroke were $1,2.5$, and $0.5 \%$ respectively. ${ }^{43,92,93}$ Hence, though associated with a small risk of major periprocedural events, the PLAATO device appeared to be effective in reducing the stroke risk equally or better than $O A C$ in patients with AF when compared with historical controls of equivalent stroke risk in a non-randomized fashion.

\section{Watchman}

Table 4 summarizes current published and presented clinical experience with the Watchman device.
First, clinical experience with the device was published in $2007 .{ }^{44}$ Thereafter, high-risk patients have been enroled into trials and registries providing data from 1139 patients with over 1500 patient-years of follow-up. The results demonstrate the safety and efficacy of this device in preventing thrombo-embolic events compared with warfarin therapy. ${ }^{45,66,88,89,94-96}$

The Watchman device is the only LAA occlusion device that has been evaluated in prospective, controlled, randomized trials examining its efficacy and safety, e.g. in 707 patients with non-valvular AF. $^{45}$ The PROTECT AF study was designed to assess the noninferiority of the device against chronic warfarin therapy. The first publication included follow-up of 1065 patient-years, ${ }^{45}$ but data on 1500 patient-years are currently available ${ }^{97}$ of whom $87 \%$ discontinued OAC at 45 days and $94 \%$ after 2 years of follow-up. Although there was a higher rate of adverse safety events in the intervention group than in the control group, due mainly to periprocedural complications (pericardial effusion and procedural stroke typically related to air embolism), most events were without long-term sequelae. Safety events in the Watchman group occurred primarily on the day of the procedure, while the event rate was lower than that of the control group after the periprocedural period. Importantly, when follow-up was extended from 600 to 1500 patient-years, there was a $46 \%$ reduction in relative risk from 2.85 to 1.53 . Longer follow-up results were recently presented with a further decrease in primary event rate and, for the first time, a survival benefit for the Watchman group when compared with the control warfarin group. ${ }^{96}$

The effect of increased operator experience is demonstrated in the CAP registry with shorter implant time, higher implant success rate, lower complication rates, and higher warfarin discontinuation rate. ${ }^{88}$

The Randomized Trial of LAA Closure vs. Warfarin for Stroke/ Thromboembolic Prevention in Patients with Nonvalvular Atrial Fibrillation (PREVAIL) study ${ }^{66}$ was designed similarly to strengthen the results of the PROTECT AF trial in more patients at somewhat higher risk treated by centres with variable experience. Its preliminary results, presented but not yet published, demonstrated low early and long-term primary and safety event rates.

In the PROTECT AF study (average $\mathrm{CHADS}_{2}$ score 2.2 and $\mathrm{CHA}_{2}$ $D_{2}$-VASc score 3.4), all patients were treated with warfarin for 45 days after device implantation to facilitate device endothelialization. Warfarin was stopped if TOE examination (performed after 45 days, 6 months, and 1 year) showed either complete occlusion of the LAA or if there was residual peridevice flow of $<5 \mathrm{~mm}$ in width. However, recent data support the safety and efficacy of LAA occlusion in patients with contraindications to even temporary anticoagulation treated with antiplatelet therapy only after device implantation. ${ }^{95}$

Peridevice flow is common after Watchman implantation. In a retrospective analysis evaluating the clinical impact of incomplete LAA sealing in patients undergoing percutaneous LAA occlusion with the Watchman device, some degree of peridevice flow was reported in $47 \%$ at 45 days and $33 \%$ at 12 months. However, the overwhelming majority of leaks were small. Peridevice flow $>3 \mathrm{~mm}$ was seen in only $12 \%$ of patients at 12 months. Most importantly, compared to patients with complete occlusion there was no difference in thrombo-embolic events in those with any peridevice flow regardless of whether or not anticoagulation was continued. Hence, small amounts of residual flow do not appear to impact safety and clinical efficacy of Watchman implantation. ${ }^{83}$ Given the small number of 


\section{Table 3 Parameters for registries of LAA occluders}

(1) Demographic data

Name or registry code

Gender

Age

(2) Type of device implanted

Watchman

ACP

Other

Previous failure of LAA occlusion device (type, date, reason)

(3) Type of atrial fibrillation

Paroxysmal

Persistent

Long-standing persistent (permanent)

(4) Cardiovascular history

Ischaemic heart disease

Congestive heart failure

Valvular heart disease

Cardiomyopathy

Arrhythmic history other than AF

(5) $\mathrm{CHADS}_{2}$ score

(6) $\mathrm{CHA}_{2} \mathrm{DS}_{2}$-VASc score

(7) HAS-BLED score

(8) Antithrombotic therapy given prior to the implant

ASA

Clopidogrel

Warfarin

Apixaban

Dabigatran

Rivaroxaban

Prasugrel

Ticagrelor

Low-molecular-weight heparin

Fondaparinux

Other

None

(9) Indication for implant

Low compliance

History of intracranial bleeding (intracerebral and subdural)

History of urinary tract bleeding

History of spontaneous bleeding other than intracranial or urinary tract bleeding (i.e. retroperitoneal haematoma)

Recurrent falls

Cognitive impairment

Use of non-steroidal anti-inflammatory drugs, steroids

Personal preference

(10) Technical data of implant

Success/failure

Size of the device implanted

Measure LAA opening, landing zone, and depth

LAA morphology (unilobar, multilobar, 'cauliflower type', chicken wing, wind sock, etc.)

\section{Table 3 Continued}

Need for device replacement during the procedure (type and size)

(11) Periprocedural complications

Death

Ischaemic stroke

Transient ischaemic attack

Haemorrhagic stroke

Pericardial effusion with tamponade

Valvular complication (i.e. mitral valve damage)

Device embolization

Bleeding

Major

Minor

Peripheral vascular complication

Pulmonary oedema

Myocardial infarction

Arrhythmia (type)

Pulmonary embolism

(12) Antithrombotic therapy at discharge and length of therapy

ASA

Clopidogrel

Warfarin

Apixaban

Dabigatran

Edoxaban

Rivaroxaban

Prasugrel

Ticagrelor

Low-molecular-weight heparin

Fondaparinux

Other

None

(13) TOE follow-up at 6 weeks, 6 months, and 1 year

Device position (as at implant)

Device-related thrombi

Para-device leak (size)

Device embolization

(14) Clinical follow-up at 6 weeks, 12 months, and yearly thereafter Death

Ischaemic stroke

Transient ischaemic attack

Haemorrhagic stroke

Device embolization

Major bleed

Minor bleed

Peripheral vascular complication

Pulmonary oedema

Myocardial infarction

Arrhythmia (type)

Pulmonary embolism

Type of antithrombotic therapy

ASA, acetylsalicylic acid. Other abbreviations as in Table 2. 


\begin{tabular}{|c|c|c|c|c|c|c|c|c|c|c|c|c|c|}
\hline Trial & Patients & $\begin{array}{l}\text { Patients } \\
\text { devicel } \\
\text { Control }\end{array}$ & Comments & $\begin{array}{l}\text { Average } \\
\text { CHADS }_{2} \\
\text { Score }\end{array}$ & $\begin{array}{l}\text { Average } \\
\text { CHA }_{2} \text { DS }_{2^{-}} \\
\text {VASc Score }\end{array}$ & $\begin{array}{l}\text { Medical } \\
\text { therapy }\end{array}$ & Efficacy events & Safety events & $\begin{array}{l}\text { Successful } \\
\text { implantation }\end{array}$ & $\begin{array}{l}\text { Mean follow- } \\
\text { up (months) }\end{array}$ & $\begin{array}{l}\text { No } \\
\text { warfarin }\end{array}$ & $\begin{array}{l}\text { Primary efficacy } \\
\text { event rate } \\
\text { (per 100 } \\
\text { patient-years) }\end{array}$ & $\begin{array}{l}\text { Safety event } \\
\text { rate }\end{array}$ \\
\hline $\begin{array}{l}\text { Pilot } \\
\text { study } 44,94\end{array}$ & 66 & $66 / 0$ & $\begin{array}{l}\text { Non-randomized } \\
\text { cohort of patients } \\
\text { undergoing } \\
\text { Watchman } \\
\text { implantation }\end{array}$ & $1.8 \pm 1.1$ & & $\begin{array}{l}\text { Warfarin plus } \\
\text { ASA for } 45 \\
\text { days, and } \\
\text { ASA for life }\end{array}$ & $\begin{array}{l}\text { Death, stroke, } \\
\text { systemic } \\
\text { embolism, and } \\
\text { major bleeding }\end{array}$ & & $88 \%$ & $73 \pm 25$ & $91 \%$ & $\begin{array}{l}\text { Actual stroke rate } \\
\text { of } 0.5 \%\end{array}$ & $\begin{array}{l}4 \text { device } \\
\text { embolizations }\end{array}$ \\
\hline $\begin{array}{l}\text { CAP } \\
\text { Registry }^{88}\end{array}$ & 460 & $460 / 0$ & $\begin{array}{l}\text { Non-randomized } \\
\text { registry of patients } \\
\text { undergoing } \\
\text { Watchman } \\
\text { implantation }\end{array}$ & $2.4 \pm 1.2$ & & $\begin{array}{l}\text { Warfarin plus } \\
\text { ASA for } 45 \\
\text { days, DAPT } \\
\text { for } 6 \\
\text { months, and } \\
\text { ASA for life }\end{array}$ & $\begin{array}{l}\text { PROTECT AF } \\
\text { protocol }\end{array}$ & $\begin{array}{l}\text { PROTECT AF } \\
\text { protocol }\end{array}$ & $95 \%$ & $25.4 \pm 10.0$ & $95 \%$ & 2 & \\
\hline Prevail $^{2}$ & 407 & $269 / 138$ & $\begin{array}{l}\text { Similar to PROTECT } \\
\text { AF }^{\mathrm{a}} \text { with revised } \\
\text { inclusion criteria }\end{array}$ & $2.6 \pm 1.0$ & & $\begin{array}{l}\text { Similar to } \\
\text { PROTECT } \\
\text { AF }\end{array}$ & $\begin{array}{l}\text { Stroke, embolism, } \\
\text { or unexplained } \\
\text { death }\end{array}$ & $\begin{array}{l}\text { Same as } \\
\text { PROTECT AF } \\
\text { within } 7 \text { days }\end{array}$ & $95.1 \%$ & $\begin{array}{l}\text { Modelled to } 18 \\
\text { months, only } \\
58 \text { actually } \\
\text { reached } \\
18 \text { months }\end{array}$ & & 1 & 4 \\
\hline
\end{tabular}

DAPT, dual antiplatelet therapy; ASA, acetylsalicylic acid; AF, atrial fibrillation.

aPrevail data are preliminary and final validation is not yet complete. 
patients with large residual leaks, however, the safety of discontinuation of anticoagulation under these circumstances remains unclear.

Gangireddy et al. ${ }^{89}$ performed an analysis of the net clinical benefit (difference between the annualized rate of serious events in the Watchman group and the rate in the warfarin group, assigning different weight to the events according to severity) of Watchman implantation in PROTECT AF and CAP. This analysis demonstrated an increased net clinical benefit with higher $\mathrm{CHADS}_{2}$ scores, especially when the Watchman device was used for secondary prevention in patients with previous events. ${ }^{89}$ The device was also effective in improving quality of life compared with warfarin therapy. ${ }^{97}$ It was cost-effective when compared with warfarin but only marginally so when compared with dabigatran. ${ }^{98}$

Two ongoing studies are evaluating the device in several hundred additional patients.

\section{Amplatzer Cardiac Plug and other Amplatzer devices}

Amplatzer devices implanted into the human atria look back at more than a 20-year history in over a million patients. They have a low propensity for device thrombosis $(<1 \%)$ in patients with sinus rhythm. This track record together with their ease of use led to their utilization for percutaneous LAA occlusion ${ }^{41}$ only a few months after the first percutaneous LAA occlusion procedure was performed with the PLAATO device. ${ }^{38}$ With the PLAATO device withdrawn, the Amplatzer devices have the longest clinical follow-up of currently available LAA occluders. $^{79}$

\section{Non-dedicated Amplatzer devices}

Experience with ASD occlusion permitted the use of Amplatzer devices for LAA occlusion under fluoroscopic guidance only. ${ }^{41,79}$ However, the lack of retaining hooks and suboptimal sheath configurations resulted in a high embolization rate $6 \%$ in the aforementioned studies). Most embolized devices were retrieved percutaneously, but in some cases surgical removal (combined with LAA occlusion) was carried out. None of the available Amplatzer devices designed for occlusion of atrial or ventricular septal defects, patent ductus arteriosus, or vascular shunts proved adequate for LAA occlusion. Therefore, a specific mould was developed consisting of a hooked lobe, a thin connector, and a proximal disc. The latter is a remnant of the initial double-disc devices and comes in handy to cover the orifice of the LAA (pacifier principle). The clinical outcome in patients with technically successful Amplatzer LAA occlusion was rewarding with 0.5 events per 100 patient-years compared with the expected 5.5 events without anticoagulation or 1.8 events with anticoagulation according to the $\mathrm{CHADS}_{2}$ score. ${ }^{99}$ All patients in this series were discharged on antiplatelet therapy only. These results have to be put into perspective of a rate of $1 \%$ no device implanted and $4 \%$ device embolization. Interestingly and somewhat surprisingly, there were no device embolizations in patients with sinus rhythm at the time of implantation.

\section{Amplatzer Cardiac Plug}

Since 2008, the dedicated ACP device with lobe sizes of $16-30 \mathrm{~mm}$ diameter (disc diameter slightly larger) and a dedicated double curve sheath with a modified pusher cable have been used almost exclusively. Initial registry data reflected the technical improvements with a reduction of the embolization rate to $\sim 2 \%^{48,68,79,99-105}$
(Table 5). Pericardial effusion leading to cardiac tamponade requiring interventions occurred in $\sim 2 \%$ as did neurological events. These figures are comparable with those obtained with the PLAATO ${ }^{43}$ or the Watchman devices. ${ }^{45,88}$ In contrast to the Watchman device, there are hardly any anatomical contraindications (with the exception of visible mobile thrombus) for an attempt at LAA occlusion with an ACP. Technical success in the first 200 registry patients was 97\% and a relevant thrombus on the device during follow-up TOE was seen in $\sim 3 \%$. The complete occlusion rate at 6 -month TOE was $99 \%$. This is considerably higher than what was achieved with the Watchman device. The difference can be explained by the ACP disc occluding the mouth of the LAA in addition to the plug in the neck (feature shared with the Watchman device). Long-term followup data are lacking but design and material of the ACP are so close to that of non-dedicated Amplatzer devices that clinical outcomes can be expected to be superimposable to those mentioned in the paragraph above and perhaps even competitive to non vitamin $\mathrm{K}$ oral anticoagulants (NOACs). ${ }^{79}$

Even with the user-friendly Amplatzer technique, LAA occlusion remains challenging and the learning curve is everything but steep, much in contrast to that of occlusion of the PFO. Notwithstanding, with growing experience the results improve. Technical modifications (more and stronger hooks, deeper lobe) and the tendency to implant larger devices more deeply should lead to improved technical results. Generally ACPs are implanted without OAC thereafter. The observed thrombosis rate still leaves room for improvement so that a brief period of $(\mathrm{N}) \mathrm{OACs}$ in patients without a contraindication may be part of future protocols.

\section{LARIAT technique}

There are but preliminary data on the use of Lariat technique. A recently published series described the results in 89 patients with $96 \%$ implant success, with 3 access related complications. Long-term follow-up revealed severe pericarditis, late stroke, and sudden death in two patients each and late pericardial effusion in one patient. ${ }^{106}$

\section{Indications for left atrial appendage occlusion}

The recommended indications for the use of LAA occluders are summarized in Figure 5. In accordance with ESC guidelines, we use the $\mathrm{CHA}_{2} \mathrm{DS}_{2}$-VASc risk score $(>1)$ as the threshold value for LAA occlusion, despite the fact that some of the evidence (mainly related to the Watchman device) Is based on $\mathrm{CHADS}_{2}$ scores $\geq 1 .{ }^{107}$ We believe that both these definitions may be used.

\section{As alternative to oral anticoagulation when oral anticoagulation is possible}

Although this population constitutes a small minority of LAA occlusion recipients today, this is the only indication that is currently based on randomized controlled data and was recently recommended by an FDA panel for approval. Contrary to FDA opinion and emerging report on the cost-effectiveness of LAA occlusion, ${ }^{98,108}$ the British National Health Service Commissioning Board ruled that the costeffectiveness and clinical effectiveness of the device are not established enough yet, and therefore the device is not funded in the UK. ${ }^{109}$ 


\begin{tabular}{|c|c|c|c|c|c|c|c|c|c|c|c|c|c|c|c|}
\hline Registry & Patients & $\begin{array}{l}\text { Mean } \\
\text { age } \\
\text { (year 5) }\end{array}$ & $\begin{array}{l}\text { Mean } \\
\text { CHADS }_{2} \\
\text { score }\end{array}$ & $\begin{array}{l}\text { Technical } \\
\text { success }\end{array}$ & Stroke & $\begin{array}{l}\text { Pericardial } \\
\text { effusion } \\
\text { conservative }\end{array}$ & $\begin{array}{l}\text { Tamponade } \\
\text { (Drainage) }\end{array}$ & $\begin{array}{l}\text { Device } \\
\text { embolization }\end{array}$ & $\begin{array}{l}\text { Death } \\
\text { (all cause) }\end{array}$ & $\begin{array}{l}\text { Total } \\
\text { adverse } \\
\text { events }\end{array}$ & $\begin{array}{l}\text { Device } \\
\text { embolization }\end{array}$ & $\begin{array}{l}\text { Pericardial } \\
\text { effusion }\end{array}$ & $\begin{array}{l}\text { Thrombus } \\
\text { on device }\end{array}$ & Stroke & Death \\
\hline $\begin{array}{l}\text { Italian } \\
\quad \text { Registrty }\end{array}$ & 100 & & & $\begin{array}{l}100 / 100 \\
100 \%\end{array}$ & 0 & & $\begin{array}{l}2 / 100 \\
2 \%\end{array}$ & 0 & 0 & $\begin{array}{l}2 / 100 \\
2 \%\end{array}$ & & & & & \\
\hline $\begin{array}{c}\text { Dual Centre, } \\
\text { Hamburg } \\
\text { Bern }\end{array}$ & 131 & & & $\begin{array}{l}131 / 131 \\
100 \%\end{array}$ & 0 & $\begin{array}{l}1 / 131 \\
1 \%\end{array}$ & 0 & 0 & 0 & $\begin{array}{l}1 / 131 \\
0.8 \%\end{array}$ & & & & & \\
\hline $\begin{array}{l}\text { ACP EU Post } \\
\text { Market } \\
\text { Registry }\end{array}$ & 204 & $74 \pm 9$ & $2.6 \pm 1.3$ & $\begin{array}{l}197 / 204 \\
97 \%\end{array}$ & 0 & & $\begin{array}{l}3 / 204 \\
1.5 \%\end{array}$ & 3 & 0 & $\begin{array}{l}6 / 204 \\
2.9 \%\end{array}$ & 1 & 0 & $\begin{array}{l}5 / 204 \\
2.4 \%\end{array}$ & & \\
\hline $\begin{array}{l}\text { Spanish } \\
\text { Registry99 }\end{array}$ & 35 & $75 \pm 6$ & $2.4 \pm 1.3$ & $\begin{array}{l}34 / 35 \\
97 \%\end{array}$ & 0 & 0 & 0 & 0 & 0 & 0 & 0 & 0 & $\begin{array}{l}5 / 35 \\
14 \%\end{array}$ & $\begin{array}{l}1 / 35 \\
3 \%\end{array}$ & $\begin{array}{l}3 / 35 \\
9 \%\end{array}$ \\
\hline $\begin{array}{l}\text { Initial } \\
\quad \text { European } \\
\text { Experience }^{48}\end{array}$ & 143 & $74 \pm 9$ & - & $\begin{array}{l}132 / 137 \\
96 \%\end{array}$ & $\begin{array}{l}3 / 143 \\
2.1 \%\end{array}$ & $\begin{array}{l}4 / 143 \\
3 \%\end{array}$ & $\begin{array}{l}5 / 143 \\
3.5 \%\end{array}$ & $\begin{array}{l}2 / 143 \\
1.4 \%\end{array}$ & 0 & $\begin{array}{l}10 / 143 \\
7 \%\end{array}$ & & & & & \\
\hline $\begin{array}{l}\text { Canadian } \\
\text { Registry }\end{array}$ & 52 & $74 \pm 8$ & $3(2-4)$ & $\begin{array}{l}51 / 52 \\
98 \%\end{array}$ & 0 & $\begin{array}{l}1 / 52 \\
2 \%\end{array}$ & $\begin{array}{l}1 / 52 \\
2 \%\end{array}$ & $\begin{array}{l}1 / 52 \\
2 \%\end{array}$ & 0 & $\begin{array}{l}2 / 52 \\
4 \%\end{array}$ & 0 & $\begin{array}{l}1 / 52 \\
2 \%\end{array}$ & 0 & $\begin{array}{l}1 / 52 \\
2 \%\end{array}$ & $\begin{array}{l}3 / 52 \\
6 \%\end{array}$ \\
\hline PROTECT AF ${ }^{45}$ & 463 & $72 \pm 9$ & $2.2 \pm 1.2$ & $\begin{array}{l}408 / 463 \\
88 \%\end{array}$ & $\begin{array}{l}5 / 463 \\
1 \%\end{array}$ & $\begin{array}{l}8 / 463 \\
1 \%\end{array}$ & $\begin{array}{l}22 / 463 \\
5 \%\end{array}$ & $\begin{array}{l}3 / 463 \\
1 \%\end{array}$ & 0 & $\begin{array}{l}36 / 463 \\
8 \%\end{array}$ & $\begin{array}{l}2 / 463 \\
0.4 \%\end{array}$ & 0 & & $\begin{array}{r}16 / 694 \\
2.3 \%\end{array}$ & $\begin{array}{l}21 / 705 \\
3.0 \%\end{array}$ \\
\hline
\end{tabular}

*Air embolism in right coronary artery, one oesophageal injury during TOE. 
Atrial fibrillation patient with indication for $\mathrm{OAC}$ for stroke/embolism prevention $\left(\mathrm{CHA}_{2} \mathrm{DS}_{2}-\mathrm{VASc}>1\right)^{*}$

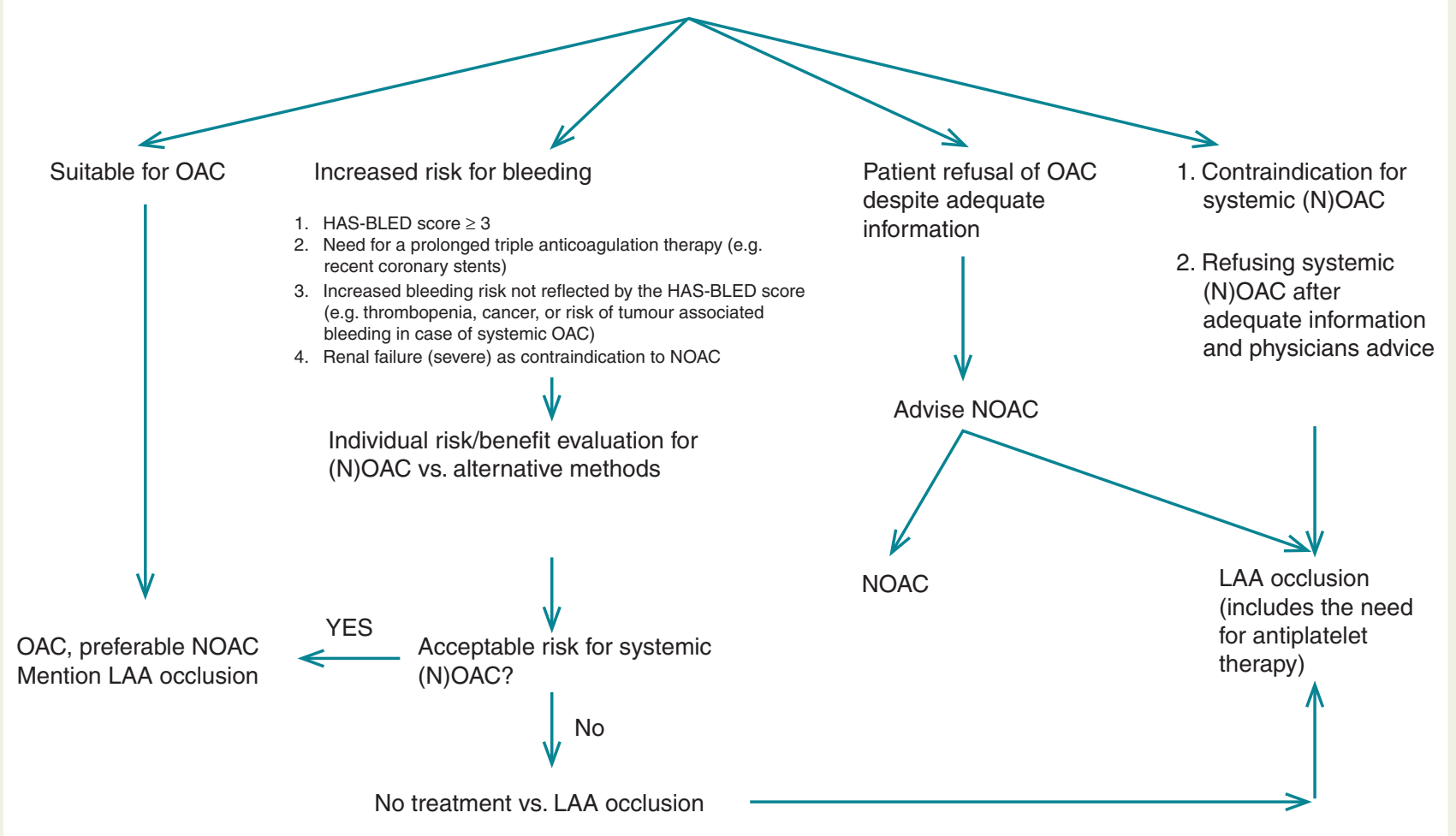

*In all: adequate and intensified rhythm control (ablation or amiodarone) in combination with continuous rhythm control by implanted devices with remote monitoring.

Figure 5 Algorithm of stroke protection in atrial fibrillation. LAA, left atrial appendage; NOAC, novel (non-Vitamin K antagonist) oral anticoagulant; OAC, oral anticoagulant.

When patients are eligible for OAC and do not exhibit an increased risk for bleeding, it is the consensus of the writing committee that the option of LAA occlusion should be mentioned to the patient while OAC currently remains the standard of therapy. Left atrial appendage occlusion should not be presented as superior treatment at this stage. Instead, the advantages and disadvantages of both treatments should be explained in detail emphasizing that randomized data currently are limited to two studies with a single device comparing it with a single agent (warfarin), an oral VKA. ${ }^{45,66}$ As far as devices other than Watchman are concerned, they are based exclusively on observational studies. Long-term outcome after LAA occlusion (taking into account periprocedural adverse events) was shown equivalent or according to the 4-year results of the PROTECT AF study even superior (in terms of stroke prevention and survival) to anticoagulation with warfarin. Yet, serious complications related to the procedure itself (including, but not limited to, the risk of death, stroke, and emergency surgery) occur. Finally, patients should be educated that NOACs are available that, compared with oral VKAs, has at least equivalent and probably improved efficacy. All tested NOACs compounds have a lower rate of intracranial and some also of overall risk for haemorrhage and they are free of the logistical challenges associated with surveillance of therapeutic levels. It should be emphasized that none of them has so far been compared with LAA occluder devices while there are ample data to show that they are equal or better than VKAs. Hence, they should be considered and discussed as an important preventive treatment alternative with much more supporting evidence than LAA occluders. Ultimately, the decision should be made by a well-informed patient in collaboration with the treating physician(s). It should be mentioned that for this indication the only device that has evidence-based support for its use is the Watchman device, whereas other devices were not systematically studied in a randomized controlled fashion.

\section{As replacement for anticoagulation when anticoagulation is not possible Patients with a contraindication to anticoagulation}

Patients with a high thrombo-embolic risk $\left(\mathrm{CHA}_{2} \mathrm{DS}_{2}\right.$-VASc score of $>2$ ) but contraindication to oral and systemic anticoagulation (e.g. history of a significant bleeding event such as intracranial or lifethreatening bleeding, the source of which cannot be eliminated) represent the most accepted clinical indication for LAA occlusion, albeit by having to extrapolate the results of the PROTECT AF study to that specific cohort. ${ }^{110}$ So far, no randomized data targeting this specific group of patients are available. Hence, our statement is based on expert consensus. This is the result of several observational studies and registries (described above in the sections dedicated to the Watchman and Amplatzer devices) suggesting that occlusion is 
safe and effective despite the absence of even temporary (N)OACs. It should be noted that dual antiplatelet therapy (DAT) is generally indicated for 1-6 months, not infrequently followed by lifelong single antiplatelet therapy. It needs to be mentioned that DAT generates a major bleeding risk comparable to that of warfarin. ${ }^{111}$ However, DAT exposure following LAA occluder implantation is only short time, thus reducing the cumulative risk of major bleeding events. Even when single-centre experience is reporting a favourable outcome after termination of any antiplatelet therapy, the majority of patients are exposed to a long-lasting single antiplatelet therapy after occluder implantation, again having the disadvantage of inducing a major and intracranial bleeding risks while, e.g. on ASA, similar to those with warfarin when stratified by the HAS-BLED score. ${ }^{112}$ In patients who cannot receive any antiplatelet agent, transepicardial LAA ligation, e.g. with the Lariat technique can be considered.

\section{Patients with an increased bleeding risk under systemic anticoagulation}

As depicted in the flow chart (Figure 5), we see the following three patient groups as possible candidates for LAA occlusion as the result of an individual risk benefit evaluation recognizing that the primarily recommended strategy is the use of OAC:

(1) In general, patients with an increased HAS-BLED score should be individually evaluated as to whether systemic OAC subjects them to an unacceptable bleeding risk and whether this high risk can be sufficiently reduced by the use of appropriately dosed NOACs (discussed below) shown to be associated with a lower bleeding risk than VKAs. Those in whom VKAs or NOACs are still considered to pose an unacceptable bleeding risk, but who remain at high stroke risk $\left(\mathrm{CHA}_{2} \mathrm{DS}_{2}\right.$-VASc score of $>2$ ), should be considered for LAA occlusion. More detailed information to perform an individual risk evaluation were discussed by Friberg et al. ${ }^{112}$ and Oleson et al. ${ }^{113}$

(2) Triple anticoagulant therapy causes a significant rise in bleeding risk. ${ }^{114-116}$ Hence, in patients with the need for a prolonged period of triple anticoagulant therapy as a result of severe coronary artery disease treated with one or more stents and AF with a high thrombo-embolic risk $\left(\mathrm{CHA}_{2} \mathrm{DS}_{2}\right.$-VASc score of $\left.>2\right)$ should be considered for percutaneous LAA occlusion.

(3) In clinical practice on a case-by-case basis, some patients with high bleeding risk who are not well characterized by the HAS-BLED score (e.g. patients with cancer or chronic inflammatory bowel disease) but have a high risk of bleeding with OAC may also be considered for LAA occlusion provided even NOACs be deemed to be associated with an unacceptable bleeding risk.

(4) In patients with end-stage renal failure, high stroke risk, and high bleeding risk, the implantation of an LAA occluder is a debatable alternative. In those patients, all NOACs are contraindicated at a creatinine clearance $<15 \mathrm{~mL} / \mathrm{min}$. The benefit of VKA or NOACs in renal failure with creatinine clearance $<15-30 \mathrm{~mL} /$ $\mathrm{min}$ is questioned due to elevated bleeding risks. The use of VKAs in patients with renal failure is controversially discussed due to an increase in tissue calcification and enhanced atherosclerosis.
Importantly, for all four above groups, we recommend the performance of an individualized risk/benefit analysis for NOACs and to consider LAA occlusion as an alternative to anticoagulation. For this analysis, it should to be taken into account that at least 1-6 months of either OAC or DAT are warranted after LAA occlusion. Thereafter, patients are typically treated with at least one antiplatelet agent. Therefore, the bleeding risk for ASA (as documented, for example, in the Apixaban versus Acetylsalicylic Acid to Prevent Strokes (AVERROES) trial) ${ }^{117}$ has to be included into the LAA occlusion strategy discussion. However, the notion that, beyond the post-procedural period, indefinite single antiplatelet therapy prevents thrombo-embolic events related to the device itself is not evidence-based, but merely the result of the assumption that many patients have concomitant risk factors for atherosclerosis and stroke irrespective of AF and any foreign body continues to pose some risk of thrombus formation even beyond expected incorporation into the surrounding tissue.

\section{As a complement to anticoagulation}

The combination of LAA occlusion and OAC is discussed and occasionally performed in patients with embolic events despite adequate OAC provided no other plausible cause (e.g. carotid disease, severe mobile aortic arch atheromata) can be identified. The ESC guidelines ${ }^{107}$ recommended approach is increasing the international normalized ratio (INR) target 2.5-3.5 in this situation, when it occurs while taking warfarin. Another discussed option is the switch from VKA to one of the NOACs. ${ }^{118-121}$ Adding an antiplatelet agent to $\mathrm{OAC}$ is performed in the clinical arena, especially when embolism occurred at elevated INRs or while taking NOACs; however, there are no data available demonstrating a positive effect on embolic events which would support this approach. Left atrial appendage occlusion could be debated as an alternative treatment in those patients, especially when AF-related embolism occurs while taking VKA with documented elevated INRs or switching to NOACs is not possible due to a NOACs contraindication like severe renal impairment.

\section{As adjunct to ablation of atrial fibrillation}

So far, few data on the combination of LAA occlusion and AF ablation in a single session have been published. ${ }^{122}$ Additional personal communications about limited single-centre experiences still do not allow a general recommendation. However, as long as no randomized data to support a significant reduction in thrombo-embolic events after successful ablation are available, in very select cases, this combination seems to be a valuable and practical approach: patients with a significant risk of thrombo-embolic events $\left(\mathrm{CHA}_{2} \mathrm{DS}_{2}-\mathrm{VASc}\right.$ score of $\left.>2\right)$ undergoing an ablation procedure to treat symptomatic $A F$, who, in addition, have a strict or relative contraindication to (N)OACs, might be acceptable candidates. Under these circumstances, the ablation itself is associated with the risk of transseptal puncture, perhaps general anaesthesia, and anticoagulation and the incremental procedural risk of $L A A$ occlusion is substantially lower than if performed as a standalone procedure even though the overall procedure is becoming longer. However, once again, patient preference after thorough discussion pointing out the absence of data supporting this strategy must be integral part of the decision-making process. 


\section{In the era of new anticoagulants}

There are no scientific data available directly comparing LAA occlusion to NOACs. Though intracranial haemorrhage may be lower with dabigatran $150 \mathrm{mg}$ orally twice daily ${ }^{121}$ or rivaroxaban $20 \mathrm{mg}$ orally once daily, ${ }^{120}$ the overall incidence of major bleeding remains similar to VKAs. Therefore, in the absence of further data, it is the opinion of this consensus panel that, at the aforementioned doses, contraindications to VKAs apply equally to dabigatran and rivaroxaban, and other NOACs (Figure 5). As an exception, low-dose (110 mg orally twice daily) dabigatran or apixaban ${ }^{119}$ have been associated with lower rates of overall major bleeding as well as intracranial haemorrhage compared with VKAs while maintaining equivalent efficacy in stroke prevention. ${ }^{121}$ Therefore, consideration of low-dose dabigatran or apixaban may be reasonable in patients at increased bleeding risk provided inclusion criteria for pivotal trials examining dabigatran or apixaban are met. A decision should be made on case-by-case basis carefully evaluating potential bleeding sources and risks and recognizing limitations (among others, the unclear safety in patients with renal dysfunction and the absence of a difference in gastrointestinal haemorrhage). In addition, currently the safety of triple therapy using any of the NOACs compared with warfarin remains to be determined. In fact, the bleeding risk reduction of dabigatran in combination with clopidogrel and ASA was only minor compared with triple therapy including warfarin. ${ }^{121}$ Though there are clear advantages both in the logistics of administration and surveillance as well as the safety and efficacy with NOACs, a head-to-head comparison to LAA occlusion has not yet been done and final conclusions favouring NOACs over LAA occlusion or vice versa cannot be made.

\section{Anticoagulation}

Although LAA occlusion is originally meant as a substitute for chronic OAC among AF patients, the selective application of anticoagulants including antithrombotics and antiplatelets for various procedureand device-related indications remains essential. Since a majority of patients subjected to LAA occlusion are at high risk for bleeding, the anticoagulation regimen should be tailored individually.

\section{Before implantation}

Mobile thrombi visualized by screening TOE are considered a contraindication to catheter-based LAA occlusion. In such cases, $\geq 4$ weeks of (N)OACs may allow thrombus resolution to be documented on repeated TOE before catheter-based LAA occlusion is attempted.

\section{During implantation}

Femoral venous puncture by itself does not necessitate anticoagulant therapy withdrawal. Nevertheless, most operators aim for a normal INR at the time of the procedure and use intravenous antithrombotic agents (mostly unfractionated heparin) during the procedure (Table 6). The antithrombotic protocol of the PROTECT AF study, ${ }^{45}$ mandated an INR $<2.0$ at the time of procedure. Acetylsalicylic acid 81-325 mg was begun at least 1 day before the procedure and weight-adjusted heparin $(70-100 \mathrm{lU} / \mathrm{kg})$ was administered after

Table 6 Anticoagulation during and after LAA occlusion

\begin{tabular}{|c|c|c|c|c|c|c|}
\hline $\begin{array}{l}\text { Devicel } \\
\text { patient }\end{array}$ & $\begin{array}{l}\text { Heparin } \\
(A C T \geq 250)\end{array}$ & $\begin{array}{l}\text { Low-molecular- } \\
\text { weight heparin }\end{array}$ & ASA & Warfarin & Clopidogrel & Comments \\
\hline $\begin{array}{l}\text { Watchman/ } \\
\text { Low } \\
\text { bleeding } \\
\text { risk }\end{array}$ & $\begin{array}{l}\text { Prior to or } \\
\text { immediately } \\
\text { after } \\
\text { transseptal } \\
\text { punctures }\end{array}$ & $\begin{array}{l}\text { Post-procedure till } \\
\qquad I N R \geq 2\end{array}$ & $\begin{array}{l}\text { Load } 500 \text { mg prior } \\
\text { to procedure if } \\
\text { not on ASA, } \\
\text { continue } 100- \\
325 \mathrm{mg} / \text { day } \\
\text { indefinitely }\end{array}$ & $\begin{array}{l}\text { Start after } \\
\text { procedure INR } \\
2-3 \text { till } 45 \text { days } \\
\text { or continue till } \\
\text { adequate } \\
\text { occlusion }{ }^{\text {a }} \text { by } \\
\text { TOE }\end{array}$ & $\begin{array}{l}\text { Start when warfarin } \\
\text { stopped continue till } \\
6 \text { months after the } \\
\text { procedure }\end{array}$ & $\begin{array}{l}\text { Some centres do not } \\
\text { withhold warfarin and } \\
\text { perform procedure } \\
\text { on therapeutic INR } \\
\text { (no data to support or } \\
\text { dispute this approach) }\end{array}$ \\
\hline $\begin{array}{l}\text { Watchman/ } \\
\text { High } \\
\text { bleeding } \\
\text { risk }\end{array}$ & $\begin{array}{l}\text { Prior to or } \\
\text { immediately } \\
\text { after } \\
\text { transseptal } \\
\text { puncture }\end{array}$ & None & $\begin{array}{l}\text { Load } 500 \mathrm{mg} \text { prior } \\
\text { to procedure if } \\
\text { not on ASA, } \\
\text { continue } 100- \\
325 \mathrm{mg} / \text { day } \\
\text { indefinitely }\end{array}$ & None & $\begin{array}{l}\text { Load } 300-600 \text { mg prior } \\
\text { to procedure if not } \\
\text { on clopidogrel, } \\
\text { continue } 1-6 \\
\text { months while } \\
\text { ensuring adequate } \\
\text { occlusion }^{\text {a }}\end{array}$ & $\begin{array}{l}\text { Clopidogrel often given } \\
\text { for shorter time in } \\
\text { extremely high-risk } \\
\text { situations. } \\
\text { Clopidogrel may } \\
\text { replace long-term } \\
\text { ASA if better } \\
\text { tolerated }\end{array}$ \\
\hline $\mathrm{ACP}$ & $\begin{array}{l}\text { Prior to or } \\
\text { immediately } \\
\text { after } \\
\text { transseptal } \\
\text { puncture }\end{array}$ & None & $\begin{array}{l}\text { Load } 500 \mathrm{mg} \text { prior } \\
\text { to procedure if } \\
\text { not on ASA, } \\
\text { continue } 100- \\
325 \mathrm{mg} / \text { day } \\
\text { indefinitely }\end{array}$ & None & $\begin{array}{l}\text { Load } 300-600 \text { mg prior } \\
\text { to procedure if not } \\
\text { on clopidogrel, } \\
\text { continue } 1-6 \\
\text { months while } \\
\text { ensuring adequate } \\
\text { occlusion }^{\text {a }}\end{array}$ & $\begin{array}{l}\text { Clopidogrel often given } \\
\text { for shorter time in } \\
\text { extremely high-risk } \\
\text { situations. } \\
\text { Clopidogrel may } \\
\text { replace long-term } \\
\text { ASA if better } \\
\text { tolerated }\end{array}$ \\
\hline
\end{tabular}

$\mathrm{ACT}$, activated clothing time; INR, international normalized ratio.

a Less than $5 \mathrm{~mm}$ leak. 
transseptal puncture to maintain an ACT $>200$ s for the duration of the procedure. ${ }^{123}$ However, some operators perform the procedure while patients are on OAC with a therapeutic INR, an approach that can neither be supported nor condemned by currently available data. Intravenous antithrombotics are generally administered at the latest immediately after traversing the interatrial septum. A weightadjusted bolus of unfractionated heparin $(70-100 \mathrm{lU} / \mathrm{kg})$ is most commonly used, which should maintain an ACT $\geq 250 \mathrm{~s}$. Left atrial appendage occlusion may be performed as part of a combined procedure for which another antithrombotic is being used, e.g. bivalirudin. This requires no further anticoagulation.

\section{After implantation}

Post-procedural anticoagulation with warfarin is recommended for the Watchman device to avoid thrombus formation on the device until completion of endocardialization, provided there are no contraindications to anticoagulation. The anticoagulation protocol of the PROTECT AF trial (OAC for 6 weeks, DAT for 6 months, and ASA for life) was adopted in the instructions for use of the Watchman device. All patients enroled in the PROTECT AF study had to be eligible for warfarin to enable randomization to either a Watchman device occlusion or chronic warfarin therapy. However, this circumstance is rather atypical for patients considered for LAA occlusion in clinical practice. A considerable proportion of them have had a bleeding complication or have a contraindication to chronic anticoagulation (VKA or NOACs), under which circumstances operators refrain from implementing a drug regimen including an oral antithrombotic and directly prescribe DAT for at least 1 month or until a 6-month TOE follow-up, modifying the anticoagulant therapy upon its result. A satisfactory result on TOE (complete LAA occlusion or small residual shunt $<5 \mathrm{~mm}$ jet width in the absence of device surface thrombi) justifies withdrawing at least one antiplatelet agent, unless otherwise indicated. Usually the other antiplatelet agent is continued indefinitely, as most patients are elderly with evidence of atherosclerotic disease, although the bleeding risk of ASA even as a standalone therapy must be considered. This treatment rationale of DAT was mainly derived from previous experience with the PLAATO device as well as ASD and PFO device occlusions and was recently confirmed by the results of the ASA-Plavix (ASAP) registry. ${ }^{95}$ In patients who underwent Watchman implantation in the ASAP registry and received clopidogrel for 6 months and ASA indefinitely without OAC, the ischaemic stroke rate was only $1.7 \%$ compared with $2.2 \%$ in the PROTECT AF device group. By arbitrary practice, it is usual to load ASA or clopidogrel naïve patients accordingly (Table 6).

The ACP banks on the good record regarding low thrombogenicity of the Amplatzer device family, ${ }^{124}$ and indicates in its instructions for use DAT only without an oral anticoagulant. The safety and feasibility of this drug regimen was shown in initial registry data for the ACP. $^{48}$

In a recently published study using the Lariat device among 89 patients, those with a contraindication to warfarin remained off warfarin, while patients with a $\mathrm{CHADS}_{2}$ score of 2 who could tolerate warfarin but had been non-compliant or had labile INR continued warfarin. Warfarin use in patients with a $\mathrm{CHADS}_{2}$ score of 1 was left to the discretion of the referring physician. For patients not on warfarin, ASA was recommended. At 1-year follow-up, 55\% of patients were still on warfarin. ${ }^{106}$

\section{Long-term}

Transoesophageal echocardiography follow-up performed after 4-6 months is highly recommended to verify outcome and define the further anticoagulant regimen. In addition, in patients with clear contraindications to warfarin it is often not possible to use warfarin even for short periods of time and they undergo device implantation followed by antiplatelet therapy only. Therefore, consideration should be given to TOE follow-up at 1 month as, theoretically, this is the crucial period for device-associated thrombus formation.

\section{In case of thrombus on the device}

Device-associated thrombus was observed in 20 of 478 successfully implanted with a Watchman device (4.2\%) in the PROTECT AF trial. ${ }^{88}$ Of these patients, however, only three had ischaemic strokes (thrombus-associated annualized stroke rate of 0.3/100 patient-years). The remainder were asymptomatic. The device-associated thrombus was mobile in 4 patients ( 3 pedunculated and 1 laminar) and nonmobile in 10. In the remaining patients, the thrombus was not further characterized. Of the three patients with a device thrombus and a stroke, one occurred in a patient with a mobile, pedunculated thrombus. For the ACP, individual cases of device-related thrombi seen on routine TOE have been described. ${ }^{125}$ For both devices, OAC for a period of weeks to months effect thrombus resolution in most cases. Therefore, anticoagulant therapy is recommended in all patients with device-associated thrombus regardless of symptoms until thrombus resolution is confirmed by follow-up TOE.

\section{In case of incomplete occlusion of the left atrial appendage}

Incomplete LAA occlusion could create a thrombus containing pocket allowing emboli to enter the systemic circulation potentially causing strokes. Based on PROTECT AF data, small residual shunts with a jet diameter $<5 \mathrm{~mm}$ are usually deemed irrelevant and may close spontaneously with time. They do not warrant further drug or device interventions. At 45 days, $14 \%$ of the PROTECT AF cohort had residual flow $>5 \mathrm{~mm}$, in whom warfarin was continued per protocol. At the 6-month TOE, the prevalence of large ( $\geq 5 \mathrm{~mm}$ ) residual leaks decreased to $8 \%$. Persistent large shunts are becoming rare with increasing operator experience and can usually be avoided by proper initial sizing and implantation techniques. Generally, when all patients with residual shunts are included into one subgroup, the stroke risk is no different compared with patients in whom the LAA is completely occluded regardless of whether or not anticoagulant therapy is continued. ${ }^{83}$ However, whether persistent large $(\geq 5 \mathrm{~mm})$ shunts deserve long-term (N)OACs or second occlusion attempts using dedicated or nondedicated occlusion devices remains at the operator's discretion.

\section{Summary, conclusions, and recommendations}

Left atrial appendage occlusion as a means to prevent thromboembolism in AF is based on the observation that the majority of 
thrombi in non-valvular AF form in this cul de sac structure. Left atrial appendage occlusion using interventional techniques has been demonstrated to be equivalent to oral VKAs in reducing thromboembolic events.

\section{Clinical evidence}

Current commercially available devices include the ACP and the Watchman and WaveCrest devices as well as the Lariat technique for percutaneous endocardial/epicardial ligation. All have shown efficacy and relative safety in achieving the goal of preventing thromboembolism in AF patients who do not wish or cannot receive OAC. The Watchman device has demonstrated non-inferiority and later superiority when compared with warfarin in a controlled randomized trial (PROTECT AF). ${ }^{45}$ The results seem to improve with increasing operator experience. Patients who are at high risk or cannot receive OAC have been treated successfully with LAA occlusion followed by antiplatelet therapy only in observational studies and registries with results comparable to the PROTECT AF trial.

\section{Standards of performance and documentation}

The procedure requires training and knowledge acquired by a structured mentoring process. Moreover, institutions entering this field should have appropriate echocardiography and anaesthesia support and, preferably also surgical backup. Operators must have experience with pericardiocentesis and autotransfusion to manage pericardial haemorrhage and tamponade. Registries are required to document implantation results, complications, and follow-up.

\section{Imaging}

Two-dimensional TOE is currently the standard imaging technique in selection of patients and follow-up assessments and, as a complement to fluoroscopy, in device sizing and selection and procedural guidance. The purpose of follow-up TOE (recommended at, e.g. 45 days, or 3-6 months) is to detect leaks and thrombi on the device. Whether other modalities such as 3D TOE or ICE, and CT or MRI will partially replace $2 \mathrm{D}$ TOE in the future for these purposes remains to be determined.

\section{Medical therapy}

The procedure is performed under full anticoagulation. Standard medical treatment following Watchman device implantation includes a VKA for at least 6 weeks followed by DAT for 6 months and a single antiplatelet drug thereafter. However, recent data suggest that Watchman implantation followed by antiplatelet therapy only (in the absence of OAC) can also be performed safely in patients at high bleeding risk. Most ACPs were implanted with DAT for several weeks to months and a single antiplatelet drug or nothing thereafter. Prolonged (N)OACs are indicated in case of a device-associated thrombus or large $(\geq 5 \mathrm{~mm})$ leak.

\section{Indications}

Despite the results of the PROTECT AF trial, OAC (with VKA or NOACs) remains the standard therapy when there is no special risk or contraindication to (N)OACs. However, the option of LAA occlusion should be discussed with the patient, including risks of the procedure and limited proof of superiority. Patients who refuse (N)OACs after thorough discussion of current data including limitations may be considered for LAA occlusion. The main indication for LAA occlusion today is a relative or absolute contraindication to (N)OACs in patients with $\mathrm{AF}$ and a $\mathrm{CHADS}_{2}$ score of $\geq 1$ or $\mathrm{CHA}_{2}$ $D S_{2}$-VASc score $\geq 2$. It is important to realize that this recommendation is based on observational studies and registries only. With increasing thrombo-embolic risk, the use of LAA occlusion becomes more attractive. To be a candidate for LAA occlusion, patients should be able to receive at least several weeks of DAT followed in most cases by lifelong single antiplatelet drug therapy. If antiplatelet therapy is not an option, percutaneous endocardial/ epicardial or minimally invasive surgical epicardial LAA occlusion may be alternatives. The use of LAA occlusion as adjunct to AF ablation and as a supplement $O A C$ seems to be reasonable but remains to be explored.

\section{Need for future research}

Several issues regarding LAA occlusion remain to be studied. The ACP and the WaveCrest device have yet to be studied in a randomized controlled trial. No device has been adequately studied in a randomized controlled fashion in a population at high risk that cannot receive (N)OACs. None of the devices has been directly compared with N NOACs. These knowledge gaps should stimulate further trials to clarify best practice under these circumstances. An LAA occlusion registry should be established by the European Heart Rhythm Association (EHRA) and European Association of Percutaneous Coronary Interventions (EAPCl) of the ESC to document real-world results of implantation and follow-up and to complete data on indications that are not well represented in current trials.

\section{Acknowledgements}

The authors wish to thank the following colleagues for their help in reviewing scientific material and assistance in writing: Stefan Bertog MD, CardioVascular Center Frankfurt, Frankfurt, Germany; Gaetano Fassini MD, Cardiac Arrhythmia Research Center, Centro Cardiologico Monzino, IRCCS, Milan, Italy; Avishay Grupper MD, Sheba Medical Center, Tel Hashomer, Israel.

Conflict of interest: A.A.K.: Direct Personal payment: St Jude Medical; Payment to your Institution: St Jude Medical. B.M.: Direct Personal payment: Astra Zeneca, Bayer, Biosensors, BMS, Boehringer-Ingelheim, Lilly St Jude Medical; Payment to your Institution: Abbott Vascular, Biotronik, Boston Scientific, Cordis, Edwards Lifesciences, Guerbet, Medtronic, St Jude Medical. C.T.: Direct Personal payment: Biosense Webster, Biotronik, Boston Scientific, Medtronic, St Jude Medical. H.S.: Direct Personal payment: none; Payment to your Institution: Access-Closure, AGA medical, Angiomed, Ardian, Arstasis, Atrium, Avinger, Bard, Boston Scientific, Bridgepoint, Cardiokinetix, Cardiomems, Coherex, Contego, CSI, CVRx, EndoCross, Endotex, Epitek, Ev3, Evalve, FlowCardia, Gardia Medical, GDS, Gore, Guidant, HLT, InSeal, Kensey Nash, Kyoto Medical, Lifetech, Lumen Biomedical, Lutonix, Maya Medical, Medinol, Medtronic, NDC, OAS, Occlutech, Osprey, Ovalis, Pathway Medical, PendraCare, Percardia, PFM, Recor, Rox Medical, Sadra Medical, SentreHeart, Sorin Group, Spectranetics, SquareOne, Trireme, Trivascular, Veryan, Viacor, Vessix. M.G.: Direct Personal payment: 
Boston Scientific; Payment to your Institution: Biotronik, Medtronic. T.L.: None. Y.B.: Direct Personal payment: Astra Zeneca, BoehringerIngelheim, Medtronic.

\section{References}

1. Stewart S, Hart C, Hole D, McMurray J. Population prevalence, incidence, and predictors of atrial fibrillation in the Renfrew/Paisley study. Heart 2001;86:516-21.

2. Go A, Hylek E, Phillips K, Chang Y, Henault L, Selby J et al. Prevalence of diagnosed atrial fibrillation in adults: national implications for rhythm management and stroke prevention: the AnTicoagulation and Risk Factors in Atrial Fibrillation (ATRIA) Study. JAMA 2001;285:2370-5.

3. Kirchhof P, Auricchio A, Bax J, Crijns H, Camm J, Diener H et al. Outcome parameters for trials in atrial fibrillation: executive summary. Europace 2007;9:1006-23.

4. Miyasaka Y, Barnes M, Gersh B, Cha S, Bailey K, Abhayaratna W et al. Secular trends in incidence of atrial fibrillation in Olmsted County, Minnesota, 1980 to 2000, and implications on the projections for future prevalence. Circulation 2006;114: 119-25.

5. Heeringa J, van der Kuip D, Hofman A, Kors J, van Herpen G, Stricker B et al. Prevalence, incidence and lifetime risk of atrial fibrillation: the Rotterdam study. Eur Heart J 2006;27:949-53.

6. Naccarelli G, Varker H, Lin J, Schulman K. Increasing prevalence of atrial fibrillation and flutter in the United States. Am J Cardiol 2009;104:1534-9.

7. Lloyd-Jones D, Wang T, Leip E, Larson M, Levy D, Vasan R et al. Lifetime risk for development of atrial fibrillation: the Framingham Heart Study. Circulation 2004; 110:1042-6.

8. Stefansdottir H, Aspelund T, Gudnason V, Arnar DO. Trends in the incidence and prevalence of atrial fibrillation in Iceland and future projections. Europace 2011;13: 1110-7.

9. Atrial Fibrillation Investigators: Atrial Fibrillation, Aspirin, Anticoagulation Study; Boston Area Anticoagulation Trial for Atrial Fibrillation Study; Canadian Atrial Fibrillation Anticoagulation Study; Stroke Prevention in Atrial Fibrillation Study; Veterans Affairs Stroke Prevention in Nonrheumatic Atrial Fibrillation Study. Risk factors for stroke and efficacy of antithrombotic therapy in atrial fibrillation. Analysis of pooled data from five randomized controlled trials. Arch Intern Med 1994; 154:1449-57.

10. Lin HJ, WolfPA, Kelly-Hayes M, Beiser AS, Kase CS, Benjamin EJ et al. Stroke severity in atrial fibrillation. The Framingham Study. Stroke 1996;27:1760-4.

11. Gage BF, Waterman AD, Shannon W, Boechler M, Rich MW, Radford MJ. Validation of clinical classification schemes for predicting stroke: results from the $\mathrm{Na}$ tional Registry of Atrial Fibrillation. JAMA 2001;285:2864-70.

12. Lip G, Nieuwlaat R, Pisters R, Lane D, Crijns H. Refining clinical risk stratification for predicting stroke and thromboembolism in atrial fibrillation using a novel risk factor-based approach: the Euro Heart Survey on atrial fibrillation. Chest 2010; 137:263-72.

13. Hart RG, Benavente O, McBride R, Pearce LA. Antithrombotic therapy to prevent stroke in patients with atrial fibrillation: a meta-analysis. Ann Intern Med 1999;131: 492-501.

14. Waldo AL, Becker RC, Tapson VF, Colgan KJ. Hospitalized patients with atrial fibrillation and a high risk of stroke are not being provided with adequate anticoagulation. J Am Coll Cardiol 2005;46:1729-36.

15. Bungard TJ, Ghali WA, Teo KK, McAlister FA, Tsuyuki RT. Why do patients with atrial fibrillation not receive warfarin? Arch Intern Med 2000;160:41-6.

16. Levine MN, Raskob G, Landefeld S, Kearon C. Hemorrhagic complications of anticoagulant treatment. Chest 2001;119:108S-21S.

17. Kirchhof P, Ammentorp B, Darius H, De Caterina R, Le Heuzey JY, Schilling RJ et al. Management of atrial fibrillation in seven European countries after the publication of the 2010 ESC Guidelines on atrial fibrillation: primary results of the PREvention of thromboemolic events-European Registry in Atrial Fibrillation (PREFER in AF). Europace 2014;16:6-14.

18. Lip GY, Laroche C, Dan GA, Santini M, Kalarus Z, Rasmussen LH et al. A prospective survey in European Society of Cardiology member countries of atrial fibrillation management: baseline results of EURObservational Research Programme Atrial Fibrillation (EORP-AF) Pilot General Registry. Europace 2014;16:308-19.

19. Watson T, Shantsila E, Lip GY. Mechanisms of thrombogenesis in atrial fibrillation: Virchow's triad revisited. Lancet 2009;373:155-66.

20. Boldt A, Wetzel U, Lauschke J, Weigl J, Gummert J, Hindricks G et al. Fibrosis in left atrial tissue of patients with atrial fibrillation with and without underlying mitral valve disease. Heart 2004;90:400-5.

21. Frustaci A, Chimenti C, Bellocci F, Morgante E, Russo M, Maseri A. Histological substrate of atrial biopsies in patients with lone atrial fibrillation. Circulation 1997;96: 1180-4.

22. Goldsmith I, KumarP, Carter P, Blann A, Patel R, Lip G. Atrial endocardial changes in mitral valve disease: a scanning electron microscopy study. Am Heart J 2000;140: 777-84.
23. Kahn SR, Solymoss S, Flegel K. Nonvalvular atrial fibrillation: evidence for a prothrombotic state. CMAJ 1997;157:673-81.

24. Inoue H, Nozawa T, Okumura K, Jong-Dae L, Shimizu A, Yano K. Prothrombotic activity is increased in patients with nonvalvular atrial fibrillation and risk factors for embolism. Chest 2004;126:687-92.

25. Handke M, Harloff A, Hetzel A, Olschewski M, Bode C, Geibel A. Left atrial appendage flow velocity as a quantitative surrogate parameter for thromboembolic risk: determinants and relationship to spontaneous echocontrast and thrombus formation-a transesophageal echocardiographic study in 500 patients with cerebral ischemia. J Am Soc Echocardiogr 2005;18:1366-72.

26. Pollick C, Taylor D. Assessment of left atrial appendage function by transesophageal echocardiography. Implications for the development of thrombus. Circulation 1991;84:223-31.

27. Mugge A, Kuhn H, Nikutta P, Grote J, Lopez J, Daniel W. Assessment of left atrial appendage function by biplane transesophageal echocardiography in patients with nonrheumatic atrial fibrillation: identification of a subgroup of patients at increased embolic risk. J Am Coll Cardiol 1994;23:599-607.

28. Sahin T, Ural D, Kilic T, Bildirici U, Kozdag G, Agacdiken A et al. Evaluation of left atrial appendage functions according to different etiologies of atrial fibrillation with a tissue Doppler imaging technique by using transesophageal echocardiography. Echocardiography 2009;26:171-81.

29. Blackshear J, Odell J. Appendage obliteration to reduce stroke in cardiac surgical patients with atrial fibrillation. Ann Thorac Surg 1996;61:755-9.

30. Zabalgoitia M, Halperin J, Pearce L, BlackshearJ, Asinger R, Hart R. Transesophageal echocardiographic correlates of clinical risk of thromboembolism in nonvalvular atrial fibrillation. Stroke Prevention in Atrial Fibrillation III Investigators. J Am Coll Cardiol 1998;31:1622-6.

31. Takada T, Yasaka M, Nagatsuka K, Minematsu K, Yamaguchi T. Blood flow in the left atrial appendage and embolic stroke in nonvalvular atrial fibrillation. Eur Neurol 2001;46:148-52.

32. Tamura H, Watanabe T, Nishiyama S, Sasaki S, Wanezaki M, Arimoto T et al. Prognostic value of low left atrial appendage wall velocity in patients with ischemic stroke and atrial fibrillation. J Am Soc Echocardiogr 2012;25:576-83.

33. Di Biase L, Santangeli P, Anselmino M, Mohanty P, Salvetti I, Gili S et al. Does the left atrial appendage morphology correlate with the risk of stroke in patients with atrial fibrillation? Results from a multicenter study. J Am Coll Cardiol 2012;60:531-8.

34. Madden J. Resection of the left auricular appendix; a prophylaxis for recurrent arterial emboli. J Am Med Assoc 1949;140:769-72.

35. Landymore R, Kinley C. Staple closure of the left atrial appendage. Can J Surg 1984; 27:144-5.

36. Johnson WD, Ganjoo AK, Stone CD, Srivyas RC, Howard M. The left atrial appendage: our most lethal human attachment! Surgical implications. Eur J Cardiothorac Surg 2000;17:718-22

37. Katz E, Tsiamtsiouris T, Applebaum R, Schwartzbard A, Tunick P, Kronzon I. Surgical left atrial appendage ligation is frequently incomplete: a transesophageal echocardiograhic study. J Am Coll Cardiol 2000;36:468-71.

38. Sievert H, Lesh M, Trepels T, Omran H, Bartorelli A, Della Bella P et al. Percutaneous left atrial appendage transcatheter occlusion to prevent stroke in high-risk patients with atrial fibrillation: early clinical experience. Circulation 2002;105 1887-9.

39. Blackshear J, Johnson W, Odell J, Baker V, Howard M, Pearce L et al. Thoracoscopic extracardiac obliteration of the left atrial appendage for stroke risk reduction in atrial fibrillation. J Am Coll Cardiol 2003;42:1249-52.

40. Garcia-Fernandez M, Perez-David E, Quiles J, Peralta J, Garcia-Rojas I, Bermejo J et al. Role of left atrial appendage obliteration in stroke reduction in patients with mitral valve prosthesis: a transesophageal echocardiographic study. J Am Coll Cardiol 2003;42:1253-8.

41. Meier B, Palacios I, Windecker S, Rotter M, Cao QL, Keane D et al. Transcatheter left atrial appendage occlusion with Amplatzer devices to obviate anticoagulation in patients with atrial fibrillation. Catheter Cardiovasc Interv 2003;60:417-22.

42. HealeyJ, Crystal E, Lamy A, Teoh K, Semelhago L, Hohnloser S et al. Left Atrial Appendage Occlusion Study (LAAOS): results of a randomized controlled pilot study of left atrial appendage occlusion during coronary bypass surgery in patients at risk for stroke. Am Heart J 2005;150:288-93.

43. Ostermayer S, Reisman M, Kramer P, Matthews R, Gray W, Block P et al. Percutaneous left atrial appendage transcatheter occlusion (PLAATO system) to prevent stroke in high-risk patients with non-rheumatic atrial fibrillation: results from the international multi-center feasibility trials. J Am Coll Cardiol 2005;46:9-14.

44. Sick P, Schuler G, Hauptmann K, Grube E, Yakubov S, Turi Z et al. Initial worldwide experience with the Watchman left atrial appendage system for stroke prevention in atrial fibrillation. J Am Coll Cardiol 2007;49:1490-5.

45. Holmes D, Reddy V, Turi Z, Doshi S, Sievert H, Buchbinder M et al. Percutaneous closure of the left atrial appendage versus warfarin therapy for prevention of stroke in patients with atrial fibrillation: a randomised non-inferiority trial. Lancet 2009; 374:534-42. 
46. Lee R, Bartus K, Yakubov S. Catheter-based left atrial appendage (LAA) ligation for the prevention of embolic events arising from the LAA: initial experience in a canine model. Circ Cardiovasc Interv 2010;3:224-9.

47. Bartus K, Bednarek J, Myc J, Kapelak B, Sadowski J, Lelakowski J et al. Feasibility of closed-chest ligation of the left atrial appendage in humans. Heart Rhythm 2011;8: 188-93.

48. Park J, Bethencourt A, Sievert H, Santoro G, Meier B, Walsh K et al. Left atrial appendage closure with Amplatzer Cardiac Plug in atrial fibrillation: initial European experience. Catheter Cardiovasc Interv 2011;77:700-6.

49. Toumanides S, Sideris E, Agricola T, Moulopoulos S. Transcatheter patch occlusion of the left atrial appendage using surgical adhesives in high-risk patients with atrial fibrillation. J Am Coll Cardiol 2011;58:2236-40.

50. Shetty R, Leitner J, Zhang M. Percutaneous catheter-based left atrial appendage ligation and management of periprocedural left atrial appendage perforation with the LARIAT suture delivery system. J Invasive Cardiol 2012;24:E289-93.

51. Tsai L, Chen J, Lin L, Yang Y. Role of transesophageal echocardiography in detecting left atrial thrombus and spontaneous echo contrast in patients with mitral valve disease or non-rheumatic atrial fibrillation. J Formos Med Assoc 1990;89:270-4.

52. Manning W, Weintraub R, Waksmonski C, Haering J, Rooney P, Maslow A et al. Accuracy of transesophageal echocardiography for identifying left atrial thrombi. A prospective, intraoperative study. Ann Intern Med 1995;123:817-22.

53. Stoddard M, Dawkins P, Prince C, Ammash N. Left atrial appendage thrombus is not uncommon in patients with acute atrial fibrillation and a recent embolic event: a transesophageal echocardiographic study. J Am Coll Cardiol 1995;25:452-9.

54. BrownJ, Sadler D. Left atrial thrombi in non-rheumatic atrial fibrillation: assessment of prevalence by transesophageal echocardiography. Int J Card Imaging 1993;9: 65-72.

55. Collins L, Silverman D, Douglas P, Manning W. Cardioversion of nonrheumatic atrial fibrillation. Reduced thromboembolic complications with 4 weeks of precardioversion anticoagulation are related to atrial thrombus resolution. Circulation 1995;92:160-3

56. Tsai L, Lin L, TengJ, Chen J. Prevalence and clinical significance of left atrial thrombus in nonrheumatic atrial fibrillation. Int / Cardiol 1997;58:163-9.

57. Stoddard M, Singh P, Dawn B, Longaker R. Left atrial thrombus predicts transient ischemic attack in patients with atrial fibrillation. Am Heart J 2003;145:676-82.

58. Bernhardt P, Schmidt H, Hammerstingl C, Hackenbroch M, Sommer T, Luderitz B et al. Fate of left atrial thrombi in patients with atrial fibrillation determined by transesophageal echocardiography and cerebral magnetic resonance imaging. Am J Cardiol 2004;94:801-4.

59. Tang R, Dong J, Zhang Z, Li Z, Liu X, Kang J et al. Comparison of contrast enhanced 64-slice computed tomography and transesophageal echocardiography in detection of left atrial thrombus in patients with atrial fibrillation. J Interv Card Electrophysiol 2008;22:199-203.

60. Yamashita E, Takamatsu H, Tada H, Toide H, Okaniwa H, Takemura N et al. Transesophageal echocardiography for thrombus screening prior to left atrial catheter ablation. Circ J 2010;74:1081-6.

61. McCready J, Nunn L, Lambiase P, Ahsan S, Segal O, Rowland E et al. Incidence of left atrial thrombus prior to atrial fibrillation ablation: is pre-procedural transoesophageal echocardiography mandatory? Europace 2010;12:927-32.

62. Lewalter T, Ibrahim R, Albers B, Camm AJ. An update and current expert opinions on percutaneous left atrial appendage occlusion for stroke prevention in atrial fibrillation. Europace 2013;15:652-6.

63. Bonow R, Carabello B, Chatterjee K, de Leon AJ, Faxon D, Freed Met al. ACC/AHA 2006 guidelines for the management of patients with valvular heart disease: a report of the American College of Cardiology/American Heart Association Task Force on Practice Guidelines (writing Committee to Revise the 1998 guidelines for the management of patients with valvular heart disease) developed in collaboration with the Society of Cardiovascular Anesthesiologists endorsed by the Society for Cardiovascular Angiography and Interventions and the Society of Thoracic Surgeons. J Am Coll Cardiol 2006;48:e1-148.

64. Kanderian AS, Gillinov AM, Pettersson GB, Blackstone E, Klein AL. Success of surgical left atrial appendage closure: assessment by transesophageal echocardiography. Am Coll Cardiol 2008;52:924-9.

65. Friedman PA, Asirvatham SJ, Dalegrave C, Kinoshita M, Danielsen AJ, Johnson SB et al. Percutaneous epicardial left atrial appendage closure: preliminary results of an electrogram guided approach. J Cardiovasc Electrophysiol 2009;20:908-15.

66. Holmes DR, Kar S, Price M, Whisenant B, Sievert H, Doshi S et al. Prospective randomized evaluation of the Watchman left atrial appendage closure device in patients with atrial fibrillation versus long-term Warfarin therapy (the PREVAIL Trial). JACC 2014;64:1-12.

67. Dawson A, Asopa S, Dunning J. Should patients undergoing cardiac surgery with atrial fibrillation have left atrial appendage exclusion? Interact Cardiovasc Thorac Surg 2010;10:306-11.
68. Lam Y, Yip G, Yu C, Chan W, Cheng B, Yan B et al. Left atrial appendage closure with Amplatzer cardiac plug for stroke prevention in atrial fibrillation: initial Asia-Pacific experience. Catheter Cardiovasc Interv 2012;79:794-800.

69. Freixa X, Chan JL, Tzikas A, Garceau P, Basmadjian A, Ibrahim R. The Amplatzer Cardiac Plug 2 for left atrial appendage occlusion: novel features and first-in-man experience. Eurolntervention 2013;8:1094-8.

70. Sosa E, Scanavacca M, d'Avila A, Pilleggi F. A new technique to perform epicardial mapping in the electrophysiology laboratory. J Cardiovasc Electrophysiol 1996;7: $531-6$.

71. Klein A, Grimm R, Murray R, Apperson-Hansen C, Asinger R, Black I et al. Use of transesophageal echocardiography to guide cardioversion in patients with atrial fibrillation. N Engl J Med 2001;344:1411-20.

72. Puwanant S, Varr B, Shrestha K, Hussain S, Tang W, Gabriel R et al. Role of the CHADS2 score in the evaluation of thromboembolic risk in patients with atrial fibrillation undergoing transesophageal echocardiography before pulmonary vein isolation. J Am Coll Cardiol 2009;54:2032-9.

73. Hur J, Kim Y, Nam J, Choe K, Choi E, Shim Cet al. Thrombus in the left atrial appendage in stroke patients: detection with cardiac CT angiography-a preliminary report. Radiology 2008;249:81-7.

74. Hur J, Kim Y, Lee H, Nam J, Hong Y, Kim H et al. Cardioembolic stroke: dual-energy cardiac CT for differentiation of left atrial appendage thrombus and circulatory stasis. Radiology 2012;263:688-95.

75. Kim Y, Klein A, Halliburton S, Popovic Z, Kuzmiak S, Sola S et al. Left atrial appendage filling defects identified by multidetector computed tomography in patients undergoing radiofrequency pulmonary vein antral isolation: a comparison with transesophageal echocardiography. Am Heart J 2007;154:1199-205.

76. Shapiro M, Neilan T, Jassal D, Samy B, Nasir K, Hoffmann U et al. Multidetector computed tomography for the detection of left atrial appendage thrombus: a comparative study with transesophageal echocardiography.J Comput Assist Tomogr 2007;31: 905-9.

77. Ohyama H, Hosomi N, Takahashi T, Mizushige K, Osaka K, Kohno Met al. Comparison of magnetic resonance imaging and transesophageal echocardiography in detection of thrombus in the left atrial appendage. Stroke 2003;34:2436-9.

78. Nietlispach F, Krause R, Khattab A, Gloekler S, Schmid M, Wenaweser P et al. Ad hoc percutaneous left atrial appendage closure. J Invasive Cardiol 2013;25:683-6.

79. Nietlispach F, Gloekler S, Krause R, Shakir S, Schmid M, Khattab AA et al. Amplatzer left atrial appendage occlusion: single center 10-year experience. Catheter Cardiovasc Interv 2013;82:283-9.

80. Blendea D, Heist E, Danik S, Barrett C, Ruskin J, Mansour M. Analysis of the left atrial appendage morphology by intracardiac echocardiography in patients with atrial fibrillation. J Interv Card Electrophysiol 2011;31:191-6.

81. Nucifora G, Faletra F, Regoli F, Pasotti E, Pedrazzini G, Moccetti T et al. Evaluation of the left atrial appendage with real-time 3-dimensional transesophageal echocardiography: implications for catheter-based left atrial appendage closure. Circ Cardiovasc Imaging 2011;4:514-23.

82. Guerios E, Schmid M, Gloekler S, Khattab A, Wenaweser P, Windecker S et al. Left atrial appendage closure with the Amplatzer cardiac plug in patients with atrial fibrillation. Arq Bras Cardiol 2012;98:528-36.

83. Viles-Gonzalez J, Kar S, Douglas P, Dukkipati S, Feldman T, Horton R et al. The clinical impact of incomplete left atrial appendage closure with the Watchman device in patients with atrial fibrillation: a PROTECT AF (Percutaneous Closure of the Left Atrial Appendage Versus Warfarin Therapy for Prevention of Stroke in Patients With Atrial Fibrillation) substudy. J Am Coll Cardiol 2012;59:923-9.

84. De Ponti R, Cappato R, Curnis A, Della Bella P, Padeletti L, Raviele A et al. Transseptal catheterization in the electrophysiology laboratory: data from a multicenter survey spanning 12 years. J Am Coll Cardiol 2006;47:1037-42.

85. Fagundes R, Mantica M, De Luca L, Forleo G, Pappalardo A, Avella A et al. Safety of single transseptal puncture for ablation of atrial fibrillation: retrospective study from a large cohort of patients. J Cardiovasc Electrophysiol 2007;18:1277-81.

86. Lacomis J, Goitein O, Deible C, Moran P, Mamone G, Madan S et al. Dynamic multidimensional imaging of the human left atrial appendage. Europace 2007;9:1134-40.

87. Lip GY, Dagres N, Proclemer A, Svendsen JH, Pison L, Blomstrom-Lundqvist C; Scientific Initiative Committee, European Heart Rhythm Association. Left atrial appendage occlusion for stroke prevention in atrial fibrillation in Europe: results of the European Heart Rhythm Association survey. Europace 2013;15:141-3.

88. Reddy V, Holmes D, Doshi S, Neuzil P, Kar S. Safety of percutaneous left atrial appendage closure: results from the Watchman Left Atrial Appendage System for Embolic Protection in Patients with AF (PROTECT AF) clinical trial and the Continued Access Registry. Circulation 2011;123:417-24.

89. Gangireddy SR, Halperin JL, Fuster V, Reddy VY. Percutaneous left atrial appendage closure for stroke prevention in patients with atrial fibrillation: an assessment of net clinical benefit. Eur Heart J 2012;33:2700-8.

90. Hylek E, Evans-Molina C, Shea C, Henault L, Regan S. Major hemorrhage and tolerability of warfarin in the first year of therapy among elderly patients with atrial fibrillation. Circulation 2007;115:2689-96. 
91. Block $P$, Burstein $S$, Casale $P$, Kramer P, Teirstein P, Williams D et al. Percutaneous left atrial appendage occlusion for patients in atrial fibrillation suboptimal for warfarin therapy: 5-year results of the PLAATO (Percutaneous Left Atrial Appendage Transcatheter Occlusion) Study. J Am Coll Cardiol Cardiovasc Interv 2009:2:594-600.

92. Bayard Y, Omran H, Neuzil P, Thuesen L, Pichler M, Rowland E et al. PLAATO (Percutaneous Left Atrial Appendage Transcatheter Occlusion) for prevention of cardioembolic stroke in non-anticoagulation eligible atrial fibrillation patients: results from the European PLAATO study. Eurolntervention 2010;6:220-6.

93. ParkJ, Leithauser B, Gerk U, Vrsansky M, Jung F. Percutaneous left atrial appendage transcatheter occlusion (PLAATO) for stroke prevention in atrial fibrillation: 2-year outcomes. J Invasive Cardiol 2009;21:446-50.

94. Sick P, Turi Z, Grube E, Hauptmann K, Moebius Winkler S, Schuler G et al. Stroke prevention in non-valvular atrial fibrillation: long-term results after 6 years of the WATCHMAN Left Atrial Appendage Occlusion Pilot Study Presented at the ESC Congress 2012, Munich, Germany, 25-29 August, 2012. 2012.

95. Reddy V. Watchman LAA closure device reduces the risk of ischemic stroke in patients with AF entirely without anticoagulation. The ASA-Plavix (ASAP) Registry. Presentation of Transcatheter Therapeutics (TCT), Miami, Florida, USA. November 2012.

96. Reddy V. Late Breaking Clinical Trials. Annual Heart Rhythm Society Scientific Session 2013.

97. Holmes D, Reddy V, Turi Z, Doshi S, Sievert H, Buchbinder M et al. Quality of life assessment in the randomized PROTECT AF trial of patients at risk for stroke with non-valvular atrial fibrillation. J Am Coll Cardiol 2012;59:E240.

98. Singh SM, Micieli A, Wijeysundera HC. Economic evaluation of percutaneous left atrial appendage occlusion, dabigatran, and warfarin for stroke prevention in patients with nonvalvular atrial fibrillation. Circulation 2013;127:2414-23.

99. Schmid M, Gloeckler S, Saguner A, Wahl A, Fischer U, Arnold Met al. Transcatheter left atrial appendage closure in patients with atrial fibrillation: comparison between non-dedicated Amplatzer devices. Cardiovasc Med 2013;16:123-30.

100. Nietlispach F, Gloekler S, Khattab A, Pilgrim T, Schmid M, Wenaweser P et al. Percutaneous left atrial appendage closure. Eur J Geriatr Med 2012;3:308-11.

101. Santoro. Oral presentation. Progress in Clinical Pacing, Rome 2010.

102. Park J, Sievert H, Schillinger W, Lickfett L, Lopez-Minguez J, Heyder O et al. Acute safety results from ACP European multicenter post-market observational study. Eurolntervention 2012;8(Suppl):N163.

103. López-Minguez J, Eldoayen-Gragera J, Gonzãles-Fernãndez R, Fernãndez-Vegas C, Fuentes-Cañamero M, Millãn-Nuñez $\vee$ et al. Immediate and one-year results in 35 consecutive patients after closure of left atrial appendage with the Amplatzer cardiac plug. Rev Esp Cardiol 2013;66:90-7.

104. Gloekler S, Schmid M, Guérios E, Khattab A, Wenaweser P, Windecker S et al. Transcatheter left atrial appendage occlusion in atrial fibrillation: a 100 cases single center experience. Eurolntervention 2012;8(Suppl):N162.

105. Urena M, Rodes-Cabau J, Freixa X, Saw J, Webb JG, Freeman M et al. Percutaneous left atrial appendage closure with the AMPLATZER cardiac plug device in patients with nonvalvular atrial fibrillation and contraindications to anticoagulation therapy. J Am Coll Cardiol 2013;62:96-102.

106. Bartus K, Han F, Bednarek J, Myc J, Kapelak B, Sadowski J et al. Percutaneous left atrial appendage suture ligation using the LARIAT device in patients with atrial fibrillation: initial clinical experience. J Am Coll Cardiol 2013;62:108-18.

107. Camm AJ, Lip GY, De Caterina R, Savelieva I, Atar D, Hohnloser SH et al. 2012 focused update of the ESC Guidelines for the management of atrial fibrillation: an update of the 2010 ESC Guidelines for the management of atrial fibrillation. Developed with the special contribution of the European Heart Rhythm Association. Europace 2012;14:1385-413.

108. Amorosi SL, Armstrong S, Da Deppo L, Garfield S, Stein K. The budget impact of left atrial appendage closure compared with adjusted-dose warfarin and dabigatran etexilate for stroke prevention in atrial fibrillation. Europace 2014; 16:1131-6.

109. Clinical commissioning policy statement: Left atrial appendage (LAA) occlusion. Commissioning Board, National Health Service 2013;NHSCB/A09/PS/c.

110. Lewalter T, Kanagaratnam $P$, Schmidt B, Rosenqvist M, Nielsen-KudskJE, Ibrahim R et al. Ischaemic stroke prevention in patients with atrial fibrillation and high bleeding risk: opportunities and challenges for percutaneous left atrial appendage occlusion. Europace 2014;16:626-30.

111. Healey J, Hart R, Pogue J, Pfeffer M, Hohnloser S, De Caterina R et al. Risks and benefits of oral anticoagulation compared with clopidogrel plus aspirin in patients with atrial fibrillation according to stroke risk: the atrial fibrillation clopidogrel trial with irbesartan for prevention of vascular events (ACTIVE-W). Stroke 2008;39:1482-6.

112. Friberg L, Rosenqvist M, Lip G. Evaluation of risk stratification schemes for ischaemic stroke and bleeding in 182678 patients with atrial fibrillation: the Swedish Atrial Fibrillation cohort study. Eur Heart J 2012;33:1500-10.

113. Olesen JB, Lip GY, Lindhardsen J, Lane DA, Ahlehoff O, Hansen ML et al. Risks of thromboembolism and bleeding with thromboprophylaxis in patients with atrial fibrillation: a net clinical benefit analysis using a 'real world' nationwide cohort study. Thromb Haemost 2011;106:739-49.

114. Lip G, Piotrponikowski P, Andreotti F, Anker S, Filippatos G, Homma S et al. Thromboembolism and antithrombotic therapy for heart failure in sinus rhythm: an executive summary of a joint consensus document from the ESC Heart Failure Association and the ESC Working Group on Thrombosis. Thromb Haemost 2012;108:1009-22.

115. Faxon D, Eikelboom J, Berger P, Holmes D, Bhatt D, Moliterno D et al. Consensus document: antithrombotic therapy in patients with atrial fibrillation undergoing coronary stenting. A North-American perspective. Thromb Haemost 2011;106:572-84.

116. Huber K, Airaksinen K, Cuisset T, Marin F, Rubboli A, Lip G. Antithrombotic therapy in patients with atrial fibrillation undergoing coronary stenting: similarities and dissimilarities between North America and Europe. Thromb Haemost 2011; 106:569-71.

117. Connolly S, Eikelboom J, Joyner C, Diener H, Hart R, Golitsyn S et al. Apixaban in patients with atrial fibrillation. N Engl J Med 2011;364:806-17.

118. Connolly S, Ezekowitz M, YusufS, Eikelboom J, Oldgren J, Parekh A et al. Dabigatran versus warfarin in patients with atrial fibrillation. N Engl| Med 2009;361:1139-51.

119. Granger CB, Alexander JH, McMurray JJ, Lopes RD, Hylek EM, Hanna M et al. Apixaban versus warfarin in patients with atrial fibrillation. N EnglJ Med 2011;365:981-92.

120. Patel M, Mahaffey K, GargJ, Pan G, Singer D, Hacke W et al. Rivaroxaban versus warfarin in nonvalvular atrial fibrillation. N EnglJ Med 2011;365:883-91.

121. Eikelboom J, Wallentin L, Connolly S, Ezekowitz M, Healey J, Oldgren J et al. Risk of bleeding with 2 doses of dabigatran compared with warfarin in older and younger patients with atrial fibrillation: an analysis of the randomized evaluation of longterm anticoagulant therapy (RE-LY) trial. Circulation 2011;123:2363-72.

122. Swaans M, Post M, Rensing B, Boersma L. Ablation for atrial fibrillation in combination with left atrial appendage closure: first results of a feasibility study. J Am Heart Assoc 2012;1:e002212.

123. Fountain R, Holmes D, Chandrasekaran K, Packer D, Asirvatham S, Van Tassel R et al. The PROTECT AF (WATCHMAN Left Atrial Appendage System for Embolic PROTECTion in Patients with Atrial Fibrillation) trial. Am Heart J 2006; 151:956-61.

124. Krumsdorf U, Ostermayer S, Billinger K, Trepels T, Zadan E, Horvath K et al. Incidence and clinical course of thrombus formation on atrial septal defect and patient foramen ovale closure devices in 1,000 consecutive patients. Am Coll Cardiol 2004; 43:302-9.

125. Cruz-Gonzalez I, Martin Moreiras J, Garcia E. Thrombus formation after left atrial appendage exclusion using an Amplatzer cardiac plug device. Catheter Cardiovasc Interv 2011;78:970-3. 